\title{
Altering the properties of the magnetic Co ferrite nanoparticles fabricated by modified inverse coprecipitation for high-frequency applications
}

Rabea Al-Kershi ( $\nabla$ rkershi1@gmail.com)

Ibb University https://orcid.org/0000-0001-7634-8925

S. H. Aldirham

King Khalid University

\section{Research Article}

Keywords: CoZn ferrite nanoparticles, Ferro-fluids, Structural, Magnetic, Electrical and Dielectric parameters, optical band gab (Eg)

Posted Date: April 28th, 2020

DOl: https://doi.org/10.21203/rs.3.rs-24757/v1

License: (c) (i) This work is licensed under a Creative Commons Attribution 4.0 International License.

Read Full License 


\title{
Altering the properties of the magnetic Co ferrite nanoparticles fabricated by modified inverse coprecipitation for high-frequency applications
}

\author{
R. M. Kershi ${ }^{a, b}$, S. H. Aldirham ${ }^{a}$
}

a Physics Department, Faculty of Science, King Khalid University, Abha, Saudi Arabia. Email: rkershi1@gmail.com

b Physics Department, Faculty of Science, Ibb University, Ibb, Yemen.

\begin{abstract}
Magnetic Co ferrite nanoparticles doped with non-magnetic ions $\left(\mathrm{Zn}^{2+}\right)$ fabricated by modified inverse coprecipitation technique. X-ray calculations show that the average crystallite size (D) and the average lattice constant (a) of CoZn ferrite nanoparticles increase from 32.33 to $52.87 \mathrm{~nm}$ and from 8.39 to $8.41 \AA$ respectively with increasing non-magnetic $\mathrm{Zn}^{2+}$ ions from 0.00 to 0.55 . Morphological forms and $\mathrm{M}-\mathrm{O}$ at $\mathrm{A}$ and $\mathrm{B}$ sites studied by SEM and FT-IR spectroscopy. Measurements of the structural, optical, electrical and magnetic characterization of the $\mathrm{CoZn}$ ferrite nanoparticles strongly depend on non-magnetic $\mathrm{Zn}^{2+}$ ions content (y). Non-magnetic ions transform Co ferrite from hard and dielectric nature to soft and semiconductor nature. Values of Coercivity and the remanence decrease as non-magnetic $\mathrm{Zn}^{2+}$ ions increases to the minimum values 955 Oe and $6 \mathrm{emu} / \mathrm{g}$ for the sample with $\mathrm{Zn}=0.55 . \mathrm{Co}_{0.45} \mathrm{Zn}_{0.55} \mathrm{Fe}_{2} \mathrm{O}_{4}$ is might be suitable for high-frequency applications where it has the smallest value of optical gap, the largest value of resistivity and the lowest value of dielectric loss factor.
\end{abstract}

Keywords: CoZn ferrite nanoparticles, Ferro-fluids, Structural, Magnetic, Electrical and Dielectric parameters, optical band gab $\left(E_{g}\right)$. 


\section{Introduction}

$\mathrm{CoFe}_{2} \mathrm{O}_{4}$ receives great attention for distinctive transport and magnetic properties [1-3]. It is for instance considered in the varies applications of magneto-optical information storage media, medical diagnosis, magnetic sensors, medical resonance imaging magnetically controlled, drug delivery, catalysts, energy storage devices and optoelectronics [4-11]. In order to appropriate the properties of $\mathrm{CoFe}_{2} \mathrm{O}_{4}$ for these applications could be tuned by controlling the crystallite size (D) and by substituting subsequently the paramagnetic cobalt cations by diamagnetic cations [12]. Therefore, CoZn ferrites have attained very interest basis to the distinctive and varies properties of $\mathrm{ZnFe}_{2} \mathrm{O}_{4}$ and $\mathrm{CoFe}_{2} \mathrm{O}_{4}$ so they have excellent electromagnetic characterization and physical/chemical stability $[13,14]$. They can be used as active material in energy storage supercapacity, magnetic record medium, microwave absorption compounds and catalysis [15-19]. Waje et al. fabricated $\mathrm{Co}_{0.5} \mathrm{Zn}_{0.5} \mathrm{Fe}_{2} \mathrm{O}_{4}$ using mechanically alloyed and they studied influence of sintering temperature on its magnetic characterization [20]. M. Ajmal et al. conclude that variation of the sintering time on mixed $\mathrm{Cu}-\mathrm{Zn}$ ferrites causes appreciable changes in its structural and magnetic parameters [21]. $\mathrm{CoFe}_{2} \mathrm{O}_{4}$ nano-particles fabricated using sol gel technique and influence of dopants and ball milling on magnetic characterization studied [22]. Koseoglu et al. [23] prepared $\mathrm{ZnFe}_{2} \mathrm{O}_{4}$ by microwave method and doping it by cobalt ions. They reported that $\mathrm{ZnFe}_{2} \mathrm{O}_{4}$ with less $\mathrm{Co}$ additives have superparamagnetic character at $300 \mathrm{~K}$. The co-precipitation is an efficient technique to prepare ferrite nano-particles but, there are difficult to control size and morphology of the particles. So that, this paper aims to prepare non-magnetic ions $\mathrm{Zn}^{2+}$ substituted $\mathrm{CoFe}_{2} \mathrm{O}_{4}$ nano-particles by modified inverse co-precipitation process in medium solvent of ethylene glycol and distilled water. In this method the solution of metal ions adds to the precipitant solution, which leads to precipitate 
completely of the precursor ions in form of homogenous and nano-scale particles. This study also aims to improve the knowledge about the correlation between concentration of non-magnetic $\mathrm{Zn}^{2+}$ ions and the structural magnetic and electrical parameters of CoZn ferrites nanoparticles. In addition to study the optical behavior of ferrofluids based on CoZn ferrites nanoparticles.

\section{Experimental Techniques}

\subsection{Synthesis CoZn ferrite nanoparticles and Ferro-fluids}

Magnetic $\mathrm{CoFe}_{2} \mathrm{O}_{4}$ nano-particles doped with non-magnetic $\mathrm{Zn}^{2+}$ were fabricated by modified inverse co-precipitation procedure. The appropriated ratios of cobalt, zinc and iron nitrates salts used in synthesis approach. The metal salts weighted and mixed according to $\mathrm{Co}_{1-\mathrm{y}} \mathrm{Zn}_{\mathrm{y}} \mathrm{Fe}_{2} \mathrm{O}_{4}$ formula with $0.00 \leq \mathrm{y} \leq 0.55$ and every mixed raw materials was dissolved in deionized water and ethylene glycol (50:50) for one hour using magnetic stirrer at $21^{\circ} \mathrm{C}$. The metal solutions added to appropriate quantities of ammonia solution under high magnetic stirrer (700 rev./min.) at $21 \mathrm{oC}$ for $3 \mathrm{hrs}$. to get fine homogeneity of CoZn ferrites nano-particles. After that the fine powders precipitated and washed for many times with deionized water in order to remove $\mathrm{NO}^{3-}$ and $\mathrm{Na}^{+}$ions and salts [24]. Then the washed precursors dried in an oven at $80^{\circ} \mathrm{C}$ for one week. The dry precursors were ground by ceramic mortar and sintered in an electrical furnace at $800{ }^{\circ} \mathrm{C}$ for $3 \mathrm{hrs}$. with heat rate $10{ }^{\circ} \mathrm{C} / \mathrm{min}$ then left to cool to room temperature. Every sintered sample was ground well again for half hour to get fine and homogenous powder. Ferro-fluids samples based on CoZn ferrite nanoparticles produced by dissolving $1 \mathrm{mg}$ (for all $\mathrm{CoZn}$ ferrites samples) in $30 \mathrm{ml}$ deionized water and sonicated for 30 minutes in order to calculate the optical parameters. 


\subsection{Characterization studies}

The structural parameters of fabricated nano- powders carried out by using powder X-rays diffractometer (XRD) model a Shimadzu X-600 Japan with $\mathrm{Cu} \mathrm{K} \alpha$ $(\lambda=1.54 \AA)$ radiation. The morphologies and particles size distribution of the nanoparticles studied by using scanning electron microscope (SEM) (model: JSM 6360 LA, Japan) and imageJ software. Effect of non-magnetic $\mathrm{Zn}^{2+}$ ions on MetalOxygen bonds at tetrahedral and octahedral sites analyzed by Thermo Nicolet 6700 FTIR spectrometer at a resolution of $4 \mathrm{~cm}^{-1}$ in the range $400-4000 \mathrm{~cm}^{-1}$. JASCO V570 spectrophotometer was used to analysis the optical properties of ferro-fluids based on CoZn ferrite nanoparticles. The magnetic parameters of CoZn ferrite samples studied using Vibrating Sample Magnetometers (VSM Lakeshore model 7410) which investigated at room temperature. CoZn ferrite nano- powders pressed in the form of discs with a diameter of $14 \mathrm{~mm}$. The pellets coated by silver paste for the electrical and dielectric measurements. Using the disc samples, dc electrical conductivity $\left(\sigma_{\mathrm{DC}}\right)$ measured in the temperature range from $300 \mathrm{k}$ to $450 \mathrm{k}$ through two-probe method by Model DNM-121, SES Instruments Pvt. Ltd, Roorkee. The dielectric electrical features of the discs performed using LCR bridge meter model Agilent 4284A Precision as a function of frequency in the range from $100 \mathrm{kHz}$ to 1 $\mathrm{MHz}$ at room temperature.

\section{Results and discussion}

\subsection{Structural properties of CoZn ferrite nano-particles}

Fig.1 shows XRD graphs for the investigated CoZn ferrite nanoparticles. Styles of all CoZn ferrite samples confirmed to have unique structure of spinel phase without evidence of impurities. 


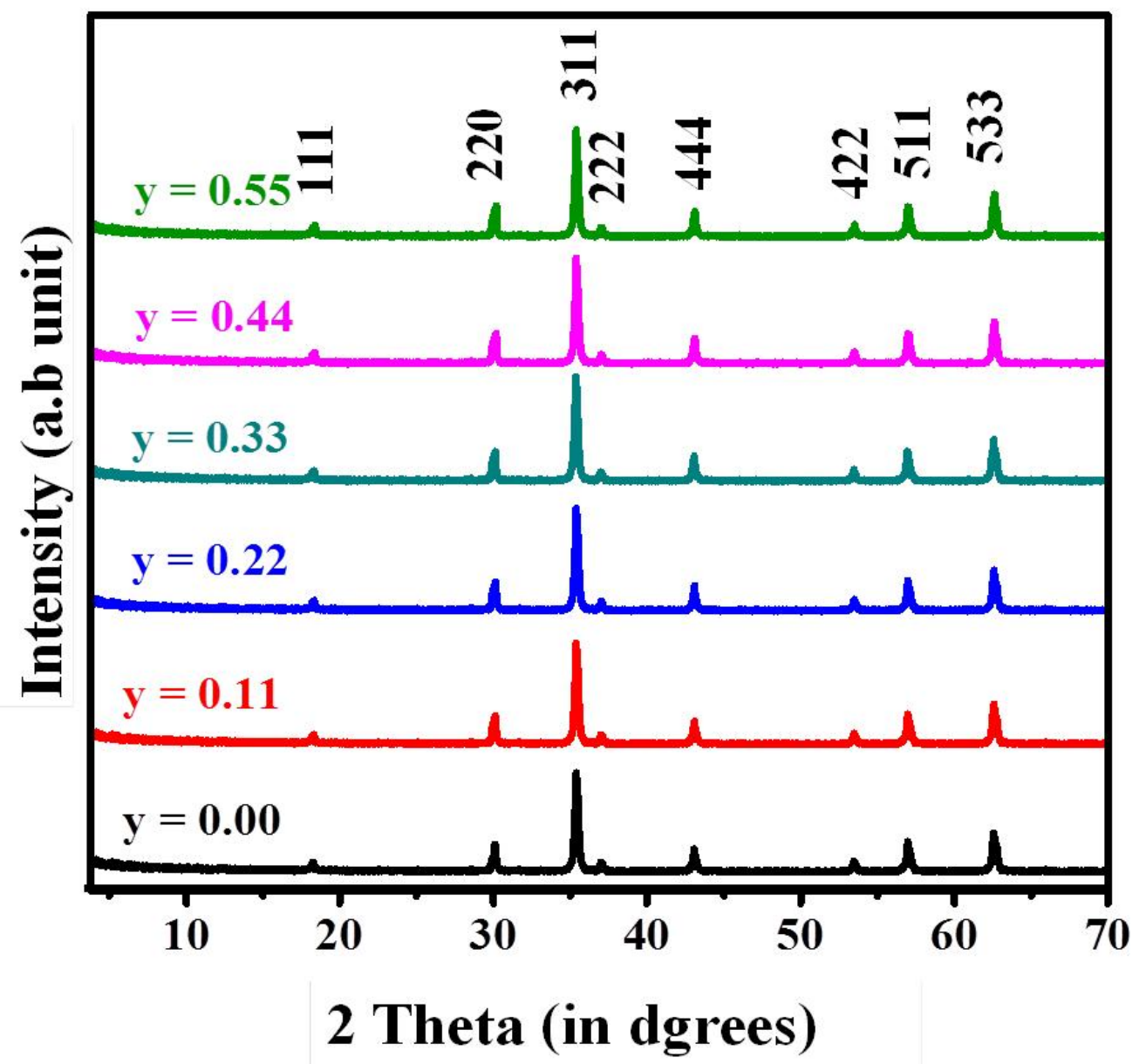

Fig.1 XRD Pattern of CoZn ferrite nanoparticles as a function of $\mathrm{Zn}^{2+}$ ions.

All XRD peaks for the CoZn ferrite samples are correspondent with the JCPDS card no. 22-1086 [25] using PANalytical XPert HighScor software. Effect of $\mathrm{Zn}^{2+}$ ions on the average lattice parameter (a) of CoZn ferrite system listed in Table 1. The average lattice parameter (a) linearly increases from $8.399 \AA$ to 8.412 $\AA$ with the increase in $\mathrm{Zn}$ from 0.00 to 0.55 . Average lattice parameter (a) of the investigated ferrites CoZn ferrite are a linear interpolation of the lattice parameter (a) of $\mathrm{CoFe}_{2} \mathrm{O}_{4}(8.38 \AA)$ [26] and $\mathrm{ZnFe}_{2} \mathrm{O}_{4}(8.44 \AA)$ [27] ferrites. This behavior of the investigated mixed spinel structure of cobalt ferrite can be explained based on 
the replacement of the smaller $\mathrm{Co}^{2+}$ ions $(\mathrm{r}=0.72 \AA)$, with larger $\mathrm{Zn}^{2+}$ ions $(\mathrm{r}=0.82$ A). Taking into account that the tetrahedral (A) sites are smaller than the octahedral (B), ones a higher occupancy of a sites by bigger metal $\mathrm{Zn}^{2+}$ ions will leads to an expansion of the structure and consequently to an increase of the lattice parameter (a) this result is consistent with previous study [28].

Values of the lattice parameter (a) for the fabricated mixed cobalt ferrites increased by increasing zinc ions so the unit cell volume (V) of $\mathrm{CoFe}_{2} \mathrm{O}_{4}$ ferrite nanoparticles which came from $\mathrm{V}=\mathrm{a}^{3}$ relation [29] increases also as seen from Table 1. $\mathrm{X}$-ray density $\left(\rho_{\mathrm{x}}\right)$ for all the prepared samples was determined by $\rho_{\mathrm{x}}=\mathrm{ZM} / \mathrm{N}_{\mathrm{A}} \mathrm{V}$ [3034]; where $\mathrm{Z}$ is the number of molecules for spinel ferrite unit cell, $\mathrm{M}$ is the molecular weight of the sample, $\mathrm{N}_{\mathrm{A}}$ is Avogadro's number and $\mathrm{V}$ is the volume of unit cell and they are tabulated in Table1. Table 1 shows that $\rho_{\mathrm{x}}$ increases from 5.26 $\mathrm{g} / \mathrm{cm}^{3}$ to $5.31 \mathrm{~g} / \mathrm{cm}^{3}$ with increasing $\mathrm{Zn}^{2+}$ ions content (y). Due to the increase in volume of the unit cell $(\mathrm{V}), \rho_{\mathrm{x}}$ should be decreased but in the present case the molecular weight (M) increases where $\mathrm{Zn}^{2+}$ has higher atomic weight (65.39 amu) than that of the $\mathrm{Co}^{2+}(58.93 \mathrm{amu})$ which overtake the effect of $\mathrm{V}$ and as a result $\rho_{\mathrm{x}}$ increases with increasing $\mathrm{Zn}^{2+}$ ions. Similar structural behavior noticed by $\mathrm{Gul}$ and Maqsood on the $\mathrm{CoFe}_{2-\mathrm{x}} \mathrm{Al}_{\mathrm{x}} \mathrm{O}_{4}$ ferrites prepared by sol-gel method [28]. The bulk density $\left(\rho_{\mathrm{b}}\right)$ was determined by $\rho_{b}=m / \pi r^{2} l$ formula where $\mathrm{m}, \mathrm{r}$ and 1 denote to mass, radius and thickness of a disc respectively. Determine the porosity for all the investigated compositions chivied according to $P=\left(1-\frac{\rho_{b}}{\rho_{x}}\right) \%[30]$ and it is recorded in Table 1 . Values of the porosity $\mathrm{p} \%$ show decreasing trend with increasing $\mathrm{Zn}$ content that justified higher values of $\rho_{\mathrm{x}}$ as compared to $\rho_{b}$. This might be owing to the being of pores in these compositions. 
Debye - Scherrer formula $D=0.9 \lambda / \beta \cos \theta, \quad(\lambda$ is the $\mathrm{x}$-ray wavelength $(1.5406 \AA), \theta$ is the diffraction angle and $\beta$ is the full width at half maximum (FWHM) used to calculated the average crystallite size (D) of all the investigated nano-particles samples. FWHM determined by Gaussian fitting of the main peak (311) through Origin Pro 2016. Fig. 2 illustrates the variation in average crystallite size with $\mathrm{Zn}^{2+}$ ions for CoZn ferrite system. An increase from $32.33 \mathrm{~nm}$ to $52.87 \mathrm{~nm}$ in the average crystallite size of the samples with increasing $\mathrm{Zn}^{2+}$ ions from 0.00 to 0.55 is observed. Dependence of the crystallite size on $\mathrm{Zn}^{2+}$ ions may be related to the site preferential occupancy of $\mathrm{Zn}$, Co and Fe elements within the spinel cubic crystal lattice.

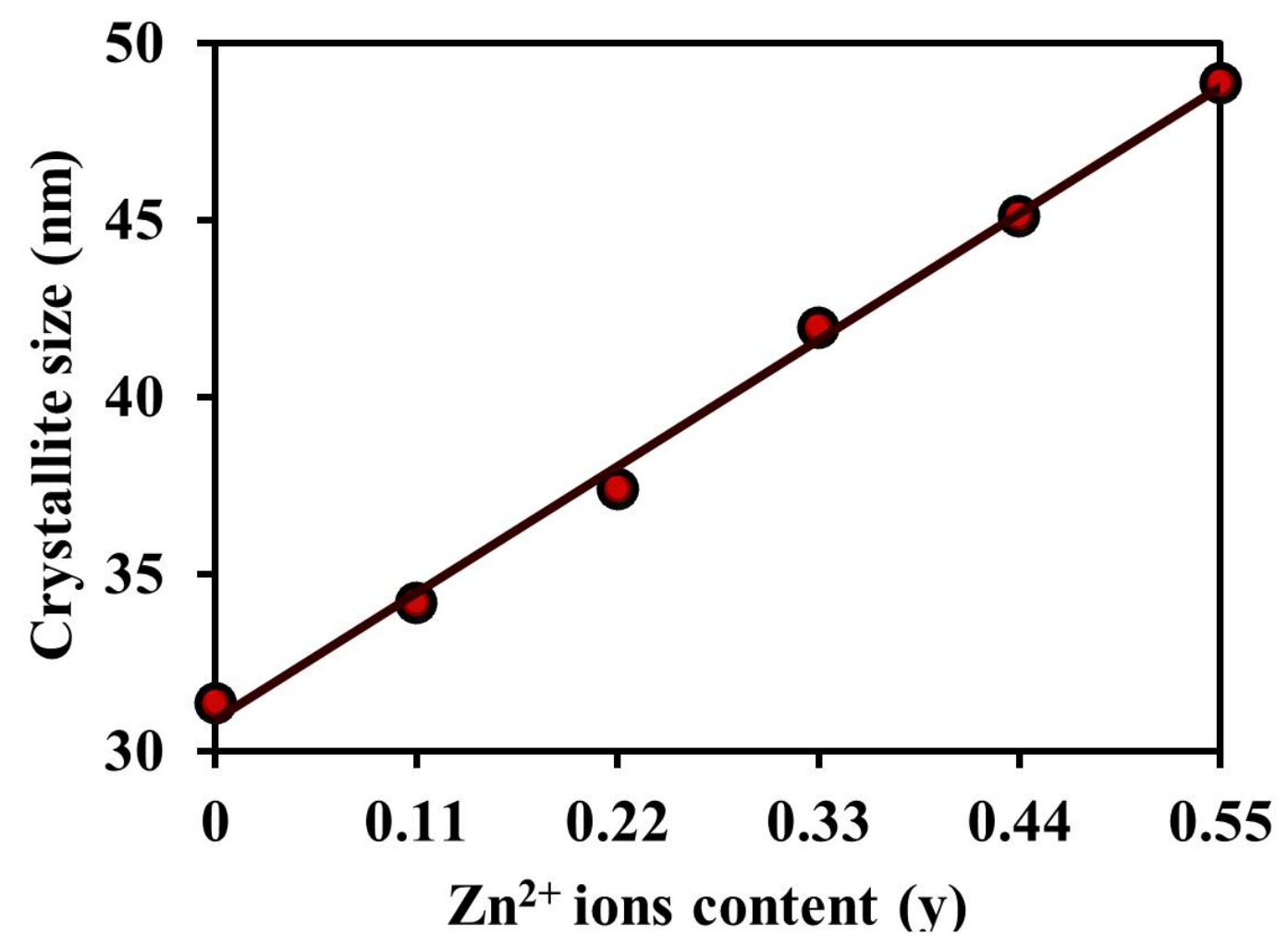

Fig. 2 The average crystallite size of CoZn ferrite nanoparticles as a function of $\mathrm{Zn}^{2+}$ ions. 
$\mathrm{Zn}^{2+}$ ions in the spinel structure have a very strong preference for tetrahedral (A) sites. $\mathrm{Fe}^{3+}$ and $\mathrm{Co}^{2+}$ ions preference both octahedral (B) and tetrahedral (A) sites with uniformly distributed amongst the different sites [3137]. $\mathrm{Zn}^{2+}$ forces $\mathrm{Fe}^{3+}$ ions to transform from A sites to B sites and the cationic preferences are not fully satisfied. Hence the increase of the crystallite size (D) from $32.33 \mathrm{~nm}$ in the case of $\mathrm{CoFe}_{2} \mathrm{O}_{4}$ to $52.87 \mathrm{~nm}$ for $\mathrm{Co}_{0.45} \mathrm{Zn}_{0.55} \mathrm{Fe}_{2} \mathrm{O}_{4}$ is may be due to the difference between the ionic radius of $\mathrm{Co}^{2+}$ ions $(\mathrm{r}=0.72 \AA)$ and $\mathrm{Zn}^{2+}(\mathrm{r}=0.82 \AA)$ [32]. Specific surface area (S) for all CoZn ferrite samples determined in term of the crystallite size (D) and density $(\rho)$ by $S=\frac{6000}{\rho D}$ relation [33]. The calculation of specific surface area (S) showed decreasing behavior with increasing $\mathrm{Zn}$ ions as illustrated in Table 1. This may be due to the strong correlation between $\mathrm{S}$ and $\mathrm{D}$ where $\mathrm{D}$ is inversely proportional to S.

Table 1 The average lattice constant $(\AA)$, the unit cell volume $\left(\AA^{3}\right)$, X-ray and bulk densities $\left(\mathrm{g} / \mathrm{cm}^{3}\right)$, porosity and specific surface area $\left(\mathrm{m}^{2} / \mathrm{g}\right)$ of CoZn ferrite nanoparticles as a function of the $\mathrm{Zn}^{2+}$ ions.

\begin{tabular}{|c|c|c|c|c|c|c|}
\hline $\mathbf{y}$ & $\mathbf{a}_{\text {exp. }}(\AA)$ & $V\left(\AA^{3}\right)$ & $\rho_{\mathrm{x}}\left(\mathrm{g} \cdot \mathrm{cm}^{-3}\right)$ & $\rho_{\mathrm{b}}\left(\mathrm{g} \cdot \mathrm{cm}^{-3}\right)$ & p \% & $S\left(m^{2} \cdot g^{-1}\right)$ \\
\hline $\mathbf{0}$ & 8.399 & 592.492 & 5.261 & 3.312 & 37.046 & 35.281 \\
\hline 0.11 & 8.4 & 592.763 & 5.273 & 3.327 & 36.905 & 33.608 \\
\hline 0.22 & 8.404 & 593.625 & 5.279 & 3.337 & 36.787 & 31.494 \\
\hline 0.33 & 8.406 & 594.125 & 5.289 & 3.346 & 36.736 & 28.109 \\
\hline 0.44 & 8.408 & 594.581 & 5.299 & 3.351 & 36.762 & 24.613 \\
\hline 0.55 & 8.412 & 595.257 & 5.308 & 3.354 & 36.812 & 21.381 \\
\hline
\end{tabular}




\subsection{Morphological analysis of CoZn ferrite nano-particles}

Scanning electron microscope (SEM) images and particles size distribution (PSD) histograms of all the synthesized CoZn ferrite samples are appeared in Fig. 3. All CoZn ferrite have nearly homogeneous nano-size particles with particles size are increasing with increasing $\mathrm{Zn}^{2+}$ ions. Nature of the surface shows aggregation coalescence character that may be refers to: the surface tension (ST) and magnetic dipoles interactions at the surface $[24,34]$. It can be also seen in Fig. 3 that the increase of $\mathrm{Zn}^{2+}$ ions leads to decrease the agglomeration between nano-particles, this behavior agrees with the report of G. Raju et al [35]. This behavior can be explained as follow; increasing the nonmagnetic ions $\left(\mathrm{Zn}^{2+}\right)$ at the expense of magnetic ions $\left(\mathrm{Co}^{2+}\right)$ leads to decrease the magnetic dipoles at the surface and magneto-static actions and hence decrease the aggregation. In addition, increasing $\mathrm{Zn}^{2+}$ ions leads to increase the crystallite size (D) and decrease the specific surface area (S) and hence decrease of surface tension (ST) and as a result decrease of the aggregation. In addition, statistical analysis of particles size (PS) and particles size distribution (PSD) of CoZn ferrite achieved using imageJ software which developed at the National Institutes of Health (NIH) [36]. From the inset histograms in Fig. 3 can be observed that the average particle size (APZ) of $\mathrm{Co}_{1-\mathrm{y}} \mathrm{Zn}_{\mathrm{y}} \mathrm{Fe}_{2} \mathrm{O}_{4}$ are 11.33, $13.92,15.22,15.57,16.16$ and $17.35 \mathrm{~nm}$ for $\mathrm{y}=0.00,0.11,0.22,0.33,0.44$ and 0.55 respectively. By comparison found that the produced values of particles size from SEM images by imageJ program and the calculated values of crystallite size from XRD data by the Scherrer equation through Gaussian fitting have the same mode where they increase with increasing $\mathrm{Zn}^{2+}$ ions. Values of SEM particles size are smaller compared with the XRD crystallite size may be due to removing backgrounds, excluding particles on edges and holes and reducing effect of high 
particles agglomeration in CoZn ferrite that's through thresholding option in image J software.

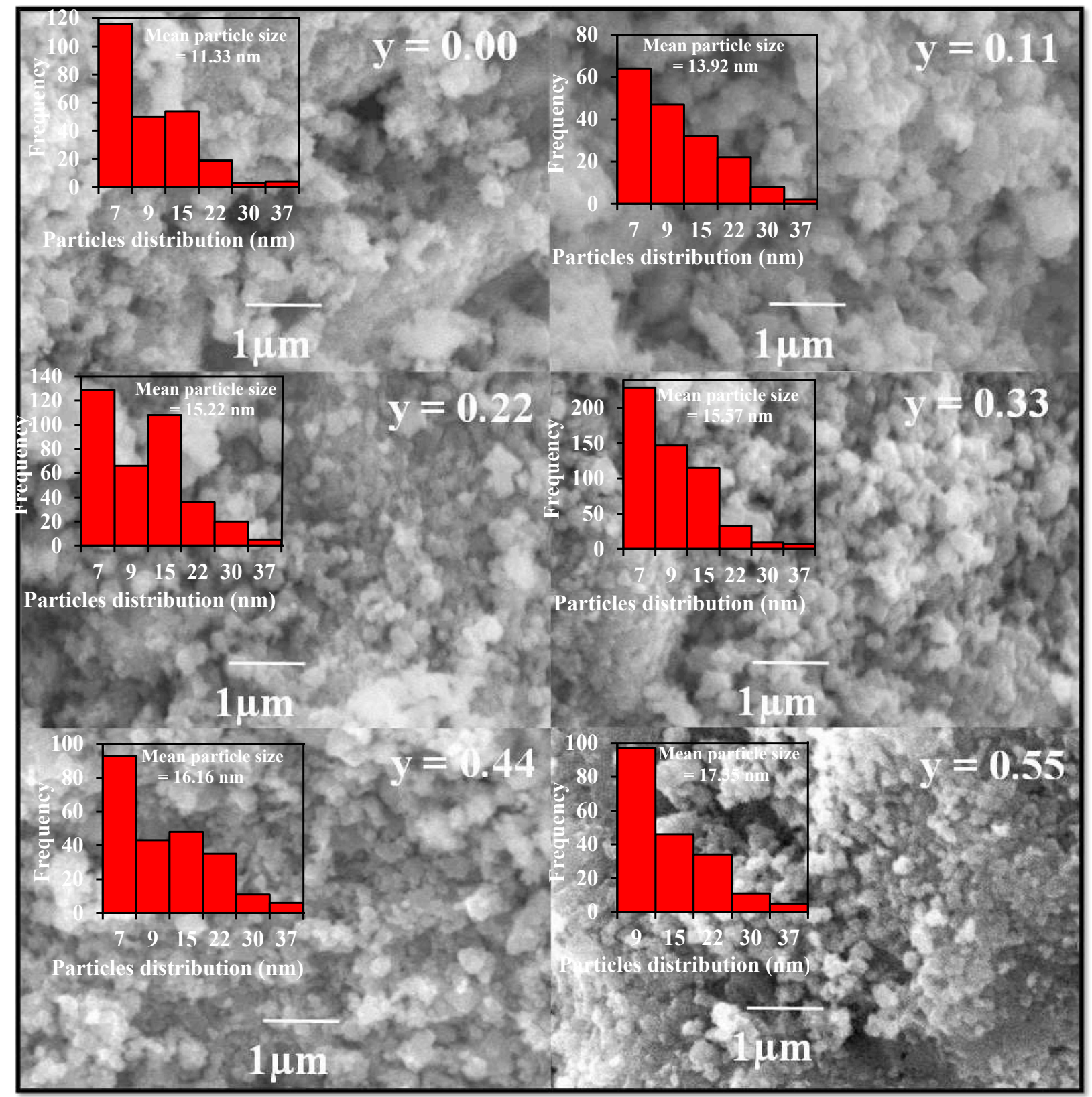

Fig. 3 SEM images and particles distribution (inset) of CoZn ferrite nanoparticles as a function of $\mathrm{Zn}^{2+}$ ions. 


\subsection{FTIR analyses of CoZn ferrite nano-particles}

Fig. 4 represents FTIR transmittance curves of the CoZn ferrite on record in the range of $400-4000 \mathrm{~cm}^{-1}$ at room temperature.

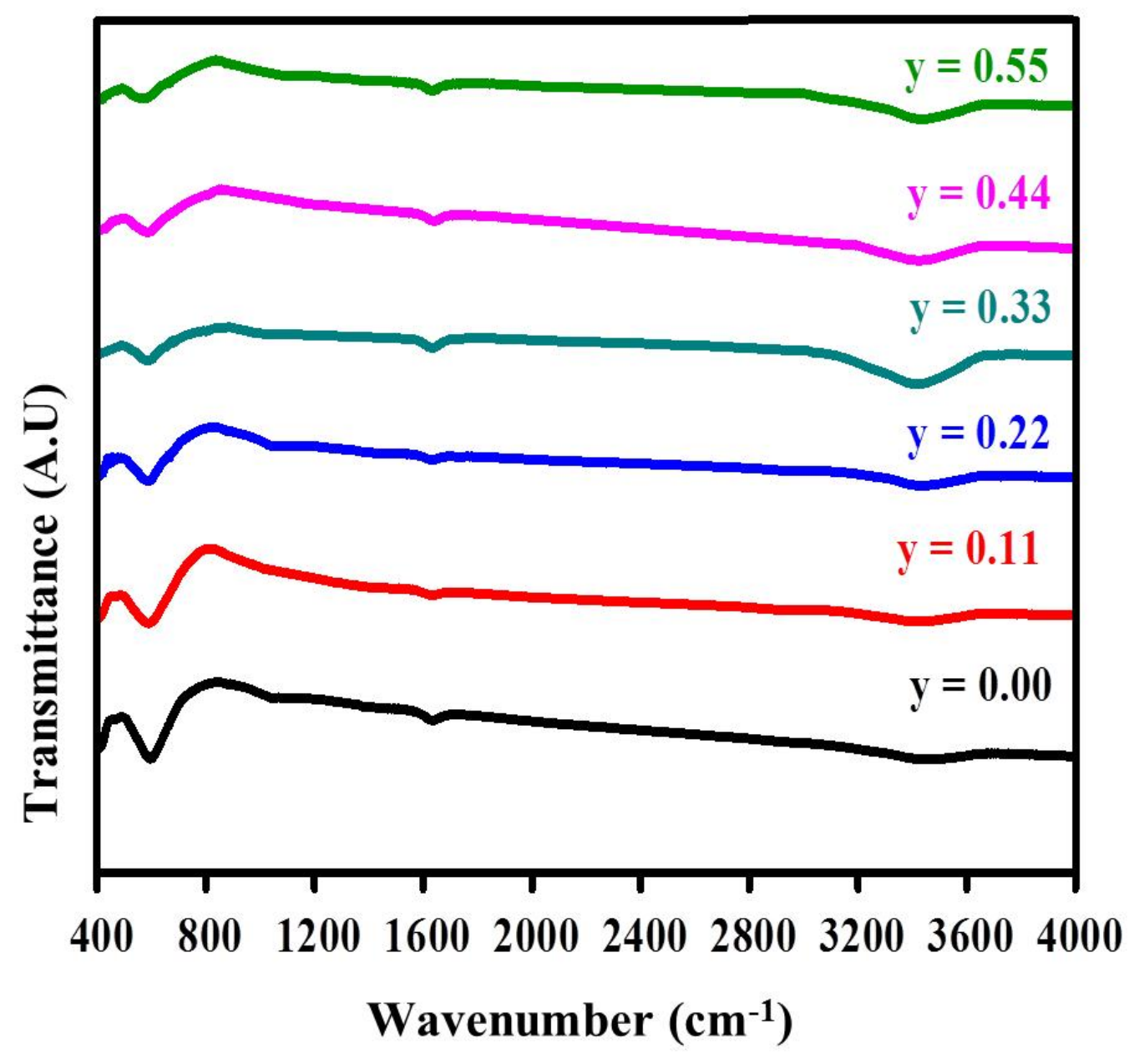

Fig. 4 FTIR spectra of CoZn ferrite nanoparticles as a function of $\mathrm{Zn}^{2+}$ ions.

The illustrated broad band at $\sim 3430 \mathrm{~cm}^{-1}$ and at $\sim 1630 \mathrm{~cm}^{-1}$ can be assigned to hydrogen - bonded $(\mathrm{O}-\mathrm{H})$ stretching vibration arising from surface hydroxyl groups and adsorbed water on the surface of CoZn ferrite nano-particles [37]. Ferrites can be considered as continuously bonded crystals where the atoms are 
bonded to all nearest neighbors by equivalent ionic bonds [38]. Cations of ferrite are distributed at two sub-lattices designated by $\mathrm{A}$ and $\mathrm{B}$ sites according to the configuration geometry of the oxygen nearest neighbors [39]. Two main absorption bands nearly around $587 \mathrm{~cm}^{-1}$ and $465 \mathrm{~cm}^{-1}$ corresponding to the stretching vibration of the metal- oxygen (M-O) at tetrahedral (A) and octahedral (B) sites $v_{\mathrm{A}}$ and $v_{\mathrm{B}}$ respectively, which confirm the consistence of spinel ferrite texture [40]. The higher values of $v_{\mathrm{A}}$ than those of $v_{\mathrm{B}}$ indicating that the normal vibration of $\mathrm{M}-\mathrm{O}$ at $\mathrm{A}$ sites is higher than that at $\mathrm{B}$ sites. This may be retained to the shorter bond length of metal - oxygen in A site than that in B site [41]. The position of $v_{A}$ and $v_{B}$ vary slightly with the variation of the metal-oxygen $(\mathrm{M}-\mathrm{O})$ distances at $\mathrm{A}$ and $\mathrm{B}$ sites. In the investigated CoZn ferrite nano-particles, A site is occupied by $\mathrm{Zn}^{2+}$ ions while $\mathrm{Co}^{2+}$ ions and $\mathrm{Fe}^{3+}$ ions partially occupy both $\mathrm{A}$ and $\mathrm{B}$ sites [31]. It seems that the $v_{\mathrm{A}}$ band shifts slightly toward the lower wave numbers with increasing $\mathrm{Zn}^{2+}$ ions, this shift indicates to weakness of the metal-oxygen $(\mathrm{M}-\mathrm{O})$ bonds in A sites because the transition of the inverse spinel (Co ferrite) toward the normal spinel (Zn ferrite) [40]. In other words, the bands become sharper when moving from the mixed spinel ferrite $\mathrm{CoFe}_{2} \mathrm{O}_{4}$ and getting closer to the normal spinel ferrite $\mathrm{ZnFe}_{2} \mathrm{O}_{4}$, similar results reported for zinc ferrites doped with magnesium [42].

In the FTIR spectra of the fabricated $\mathrm{CoFe}_{2} \mathrm{O}_{4}$ nano-particles when $\mathrm{Co}^{2+}$ ions are replaced by $\mathrm{Zn}^{2+}$ ions that have larger ionic radius and higher molecular weight and they go to A sites, $v_{\mathrm{A}}$ vibration shifts to lower wavenumber [43] from 595.93 $\mathrm{cm}^{-1}$ to $568.32 \mathrm{~cm}^{-1}$ (see Table 2). In the same time migrated $\mathrm{Fe}^{3+}$ ions to $\mathrm{B}$ sites leads to shift of $v_{\mathrm{B}}$ to higher wavenumber from $464.21 \mathrm{~cm}^{-1}$ to higher than 470.62 $\mathrm{cm}^{-1}$ (see Table 2). The phase transformation from mixed to normal spinel ferrites will be accompanied by decreasing the stretching frequencies [44]. It can be seen from Fig.4 and Table 2 for $\mathrm{Co}_{0.56} \mathrm{Zn}_{0.44} \mathrm{Fe}_{2} \mathrm{O}_{4}$ and $\mathrm{Co}_{0.45} \mathrm{Zn}_{0.55} \mathrm{Fe}_{2} \mathrm{O}_{4}$ no clear peak due 
to octahedrally coordinated metal ions has been noticed. This may be because minimum number of $\mathrm{Fe}^{2+}$ and $\mathrm{Co}^{2+}$ ions in $\mathrm{B}$ sites of this both samples. This is supported by the present results in which the frequencies $v_{\mathrm{A}}$ go to the lower values as the mixed spinel phase $\mathrm{CoFe}_{2} \mathrm{O}_{4}$ transforms into normal spinel phase $\mathrm{ZnFe}_{2} \mathrm{O}_{4}$ with increasing $\mathrm{Zn}$ content (y), similar results also noticed for nickel ferrites system doped with $\mathrm{Zn}^{2+}$ ions [45].

Table 2 The values of FTIR bands of $v_{A}$ and $v_{B}$ of CoZn ferrite nanoparticles and optical band gap of nanoferro-fluid as a function of the $\mathrm{Zn}^{2+}$ ions at room temperature.

\begin{tabular}{|c|c|c|c|}
\hline y content & $v_{\text {A }}\left(\mathrm{cm}^{-1}\right)$ & $v_{\text {B }}\left(\mathrm{cm}^{-1}\right)$ & $\mathrm{Eg}(\mathrm{eV})$ \\
\hline 0 & 595.93 & 464.21 & 3.2 \\
\hline $\mathbf{0 . 1 1}$ & 587.26 & 464.65 & 3.08 \\
\hline 0.22 & 587.56 & 464.64 & 3.04 \\
\hline 0.33 & 587.08 & 470.62 & 2.96 \\
\hline 0.44 & 597.61 & & 2.92 \\
\hline 0.55 & $\mathbf{5 6 8 . 2 3}$ & & 2.8 \\
\hline
\end{tabular}

\subsection{DC electrical conductivity of CoZn ferrite nano-particles}

Fig. 5 illustrates the relation between $\sigma_{D C}$ and absolute temperature $T(K)$ for all the fabricated CoZn ferrite nano-particles.

It can be noticed that $\sigma_{\mathrm{DC}}$ has temperature dependent for all CoZn ferrite samples where increasing $\sigma_{D C}$ cases with increasing $T(K)$ which means a semiconducting nature of the CoZn ferrite nanoparticles system. $\sigma_{\mathrm{DC}}$ of ferrites primarily studied by the role of grain boundaries (GB) since ferrites considered to be composed of conductive grains separated by the resistive GB [46]. The 
conduction in spinel ferrites occurs based of charge carriers hopping between the same element ions in different valence state [47].

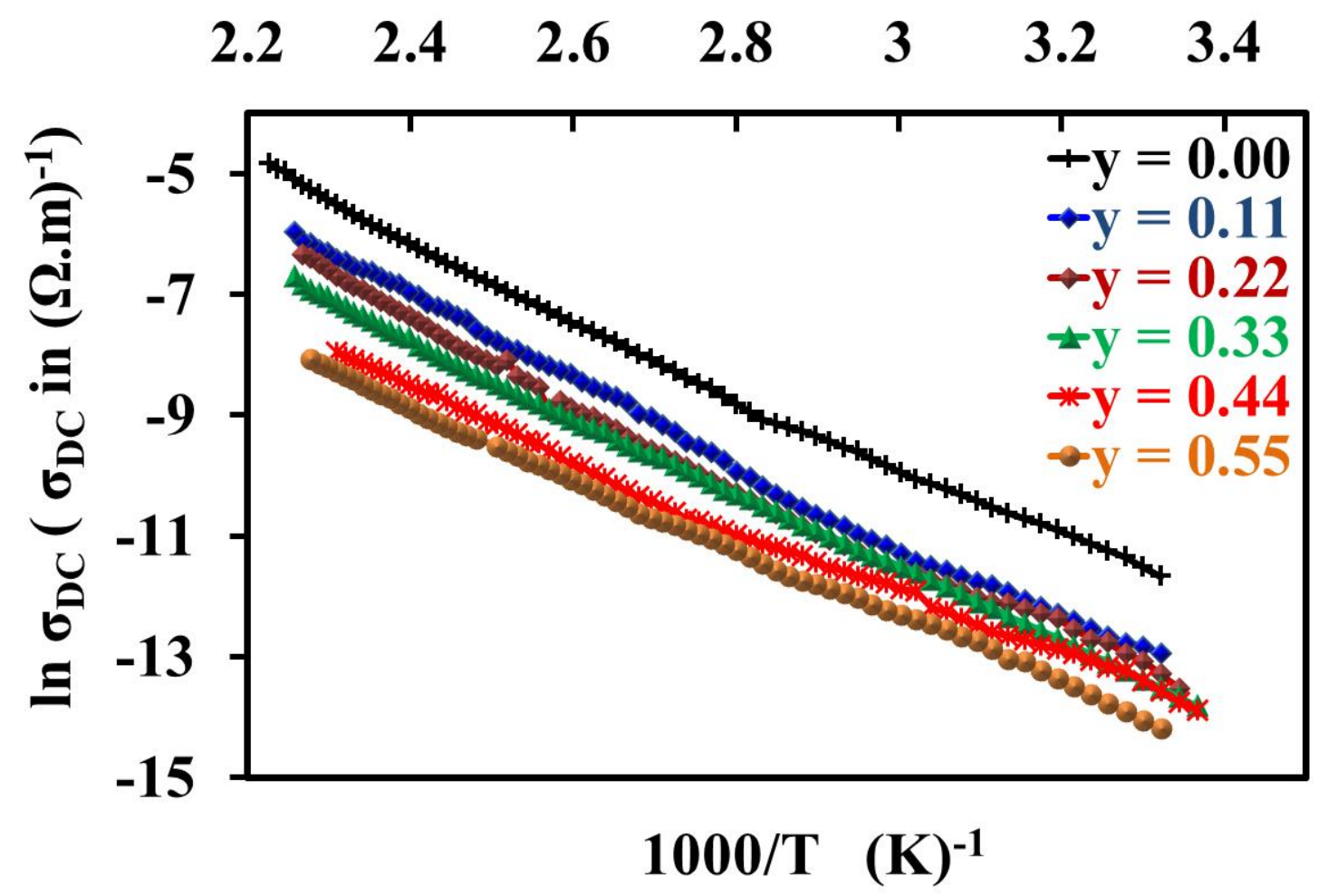

Fig. 5 The temperature dependent DC electrical conductivity of CoZn ferrite nanoparticles as a function of $\mathrm{Zn}^{2+}$ ions.

Temperature of cobalt ferrites enhances the hopping of electrons between $\mathrm{Fe}^{2+}$ and $\mathrm{Fe}^{3+}$ ions and jumping of holes $\mathrm{Co}^{2+}$ and $\mathrm{Co}^{3+}$ and therefore it increases $\sigma_{\mathrm{DC}}$ [48]. DC resistivity $\left(\rho_{\mathrm{DC}}\right)$ at $300 \mathrm{~K}$ is in order of $10^{5} \Omega \mathrm{m}$, which make the fabricated CoZn ferrite nanoparticles samples suitable for applications of high frequency. Fig. 6 shows correlation of $\sigma_{\mathrm{DC}}$ of the prepared samples with the concentration of $\mathrm{Zn}^{2+}$ ions. $\sigma_{\mathrm{DC}}$ is observed to decrease with $\mathrm{Zn}^{2+}$ content $(\mathrm{y})$. 


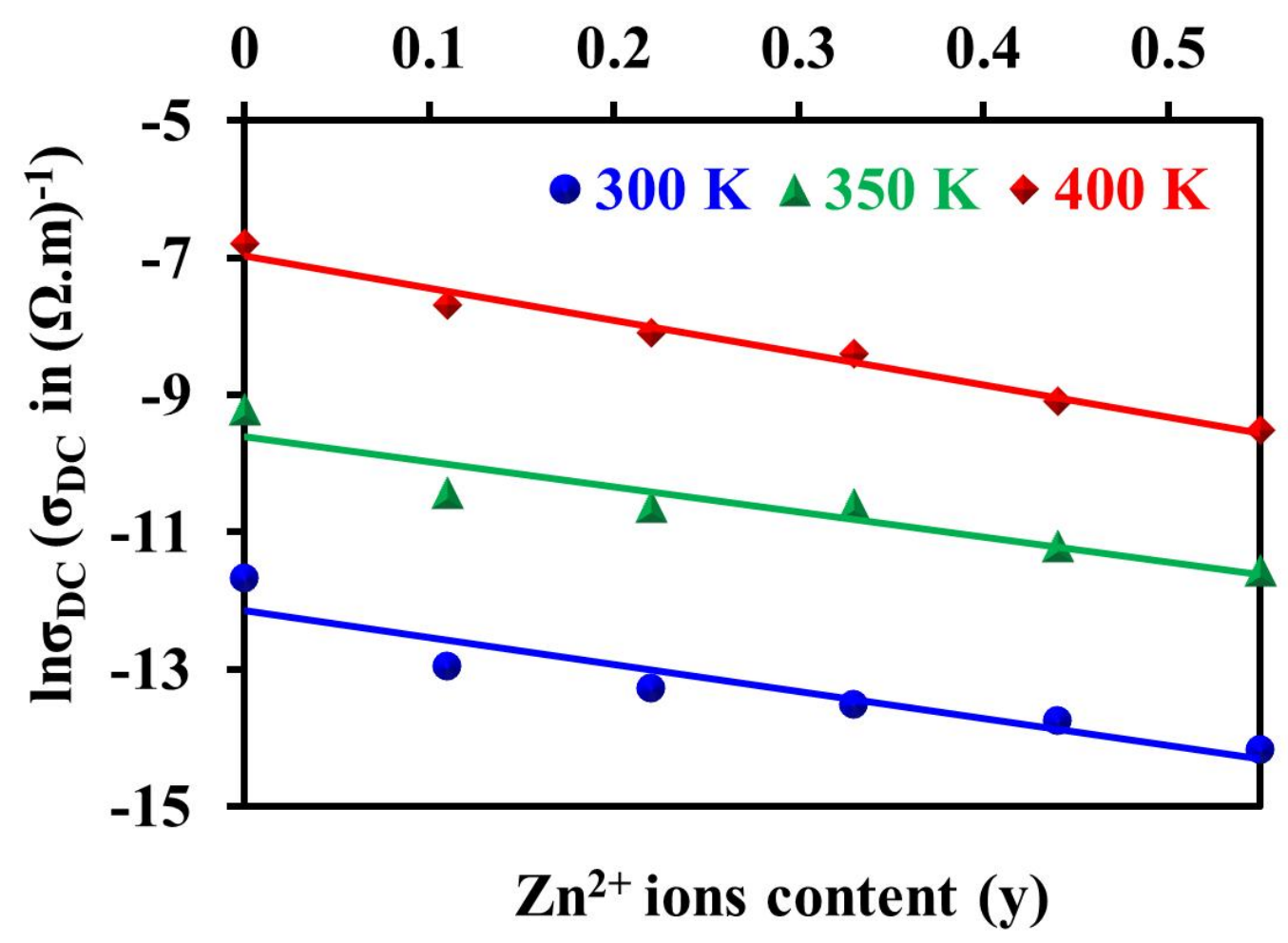

Fig. 6 DC electrical conductivity of CoZn ferrite nanoparticles versus $\mathrm{Zn}^{2+}$ ions as a function of temperature $(\mathrm{K})$.

Variation of $\sigma_{\mathrm{DC}}$ is explained based on actual location of ions in structure of the sample. Mechanism of conductivity in cobalt ferrite occurs mainly through hopping process between $\mathrm{Fe}^{2+}$ and $\mathrm{Fe}^{3+}$ ions and $\mathrm{Co}^{2+}$ and $\mathrm{Co}^{3+}$ ions in $\mathrm{B}$ sites [48]. It is well known that $\mathrm{Zn}^{2+}$ ions occupy tetrahedral (A) sites while $\mathrm{Co}^{2+}$ and $\mathrm{Fe}^{3+}$ ions occupy tetrahedral (A) and octahedral (B) sites [31]. Thus, increasing deficient of $\mathrm{Fe}^{3+}$ ions from $\mathrm{A}$ sites to $\mathrm{B}$ sites with increasing $\mathrm{Zn}^{2+}$ ions leads to decrease number of $\mathrm{Co}^{2+}$ and $\mathrm{Fe}^{3+}$ at $\mathrm{B}$ sites so this behavior gives a reason for decreasing $\sigma_{\mathrm{DC}}$.

In addition, with an increase of $\mathrm{Zn}^{2+}$ (with larger radius) ions at $\mathrm{A}$ site at the expense of cobalt (with smaller radius) ions at B site, the tetrahedral bond length increases and octahedral bond length decreases as $\mathrm{Zn}$ ions increase which increases the required activation energy $\left(\mathrm{E}_{\mathrm{a}}\right)$ to jump electrons between $\mathrm{Fe}^{2+}$ and $\mathrm{Fe}^{3+}$ ions (as 
shown from Fig. 7) therefore if $\mathrm{Zn}^{2+}$ ions increases, $\sigma_{\mathrm{DC}}$ decreases. Mechanism of charge carrier's jump depends upon $\mathrm{E}_{\mathrm{a}}$ associated with the electrical potential barrier experienced by the charge carriers during hopping. In ferrite materials $E_{a}$ is associated with the variation of drift mobility rather than the variation of density of the charge carriers. Values of the activation energies $(\Delta \mathrm{E})$ evaluated through the slopes of the linear relation of $\sigma_{\mathrm{DC}}$ (Fig. 5) were plotted in Fig. 7.

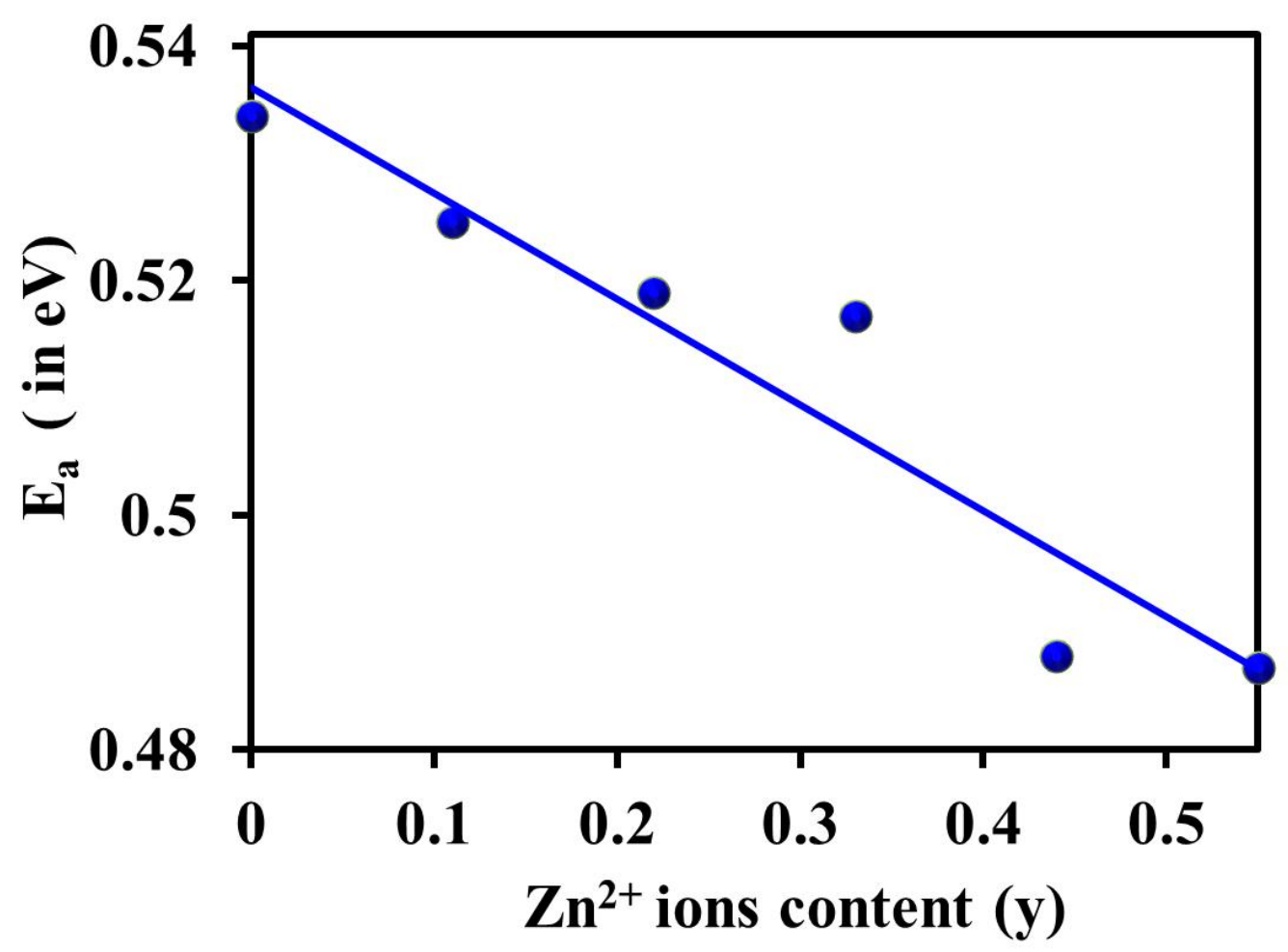

Fig. 7 Activation energy of CoZn ferrite nanoparticles as a function of $\mathrm{Zn}^{2+}$ ions.

The increase in $\mathrm{E}_{\mathrm{a}}$ of the samples with the increase of $\mathrm{Zn}^{2+}$ ions may be retains to increasing hopping length and lattice expansion. Drift mobility is expected to decrease with increase in $\mathrm{Zn}^{2+}$ which leads to decrease of $\sigma_{\mathrm{DC}}$. Drift mobility of the investigated CoZn ferrite nano-particles calculated from the measured data of $\sigma_{D C}$ by applying the relation: $\mu=\sigma_{\mathrm{DC}} /$ ne [49]; where e is the election charge and $\mathrm{n}$ is 
the charge carriers concentration. $n$ calculated by the relation: $n=\frac{N_{A} \rho_{b} n_{F e}}{M}$ [49]: where $\mathrm{N}_{\mathrm{A}}$ is Avogadro's number, $\mathrm{n}_{\mathrm{Fe}}$ is a number of iron atoms present in the chemical formula, $\rho_{b}$ is the bulk density and $M$ is the molecular weight of the compound.

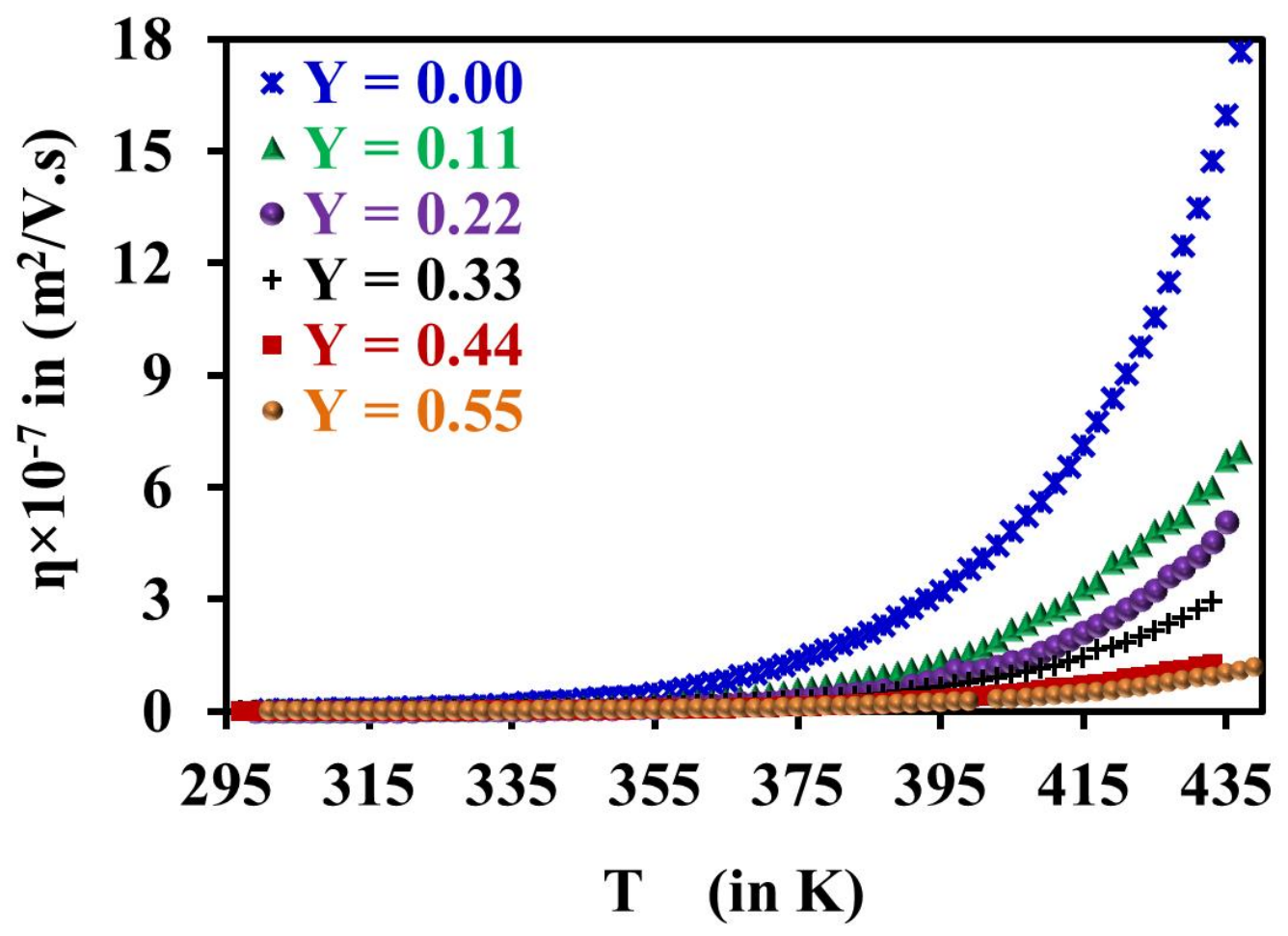

Fig. 8 The temperature dependent DC mobility of CoZn ferrite nanoparticles as a function of $\mathrm{Zn}^{2+}$ ions.

Fig. 8 illustrates the relation between the mobility and absolute temperature $\mathrm{T}$ (K) of all the fabricated samples. Drift mobility has low value at low temperatures $\mathrm{T}(\mathrm{K})$ and it has high value at high $\mathrm{T}(\mathrm{K})$ where it increases sharply with the increase in $\mathrm{T}(\mathrm{K})$. 


\subsection{AC electrical conductivity of CoZn ferrite nano-particles}

It is well known that $\sigma_{\mathrm{AC}}$ in disordered solids is directly proportional to frequency $\omega$. Alder and Feinleib [50] reported that $\sigma_{\mathrm{AC}}$ depends on $\omega . \ln \left(\sigma_{\mathrm{AC}}\right)$ versus $\ln (\omega)$ for CoZn ferrite is shown in Fig. 9.

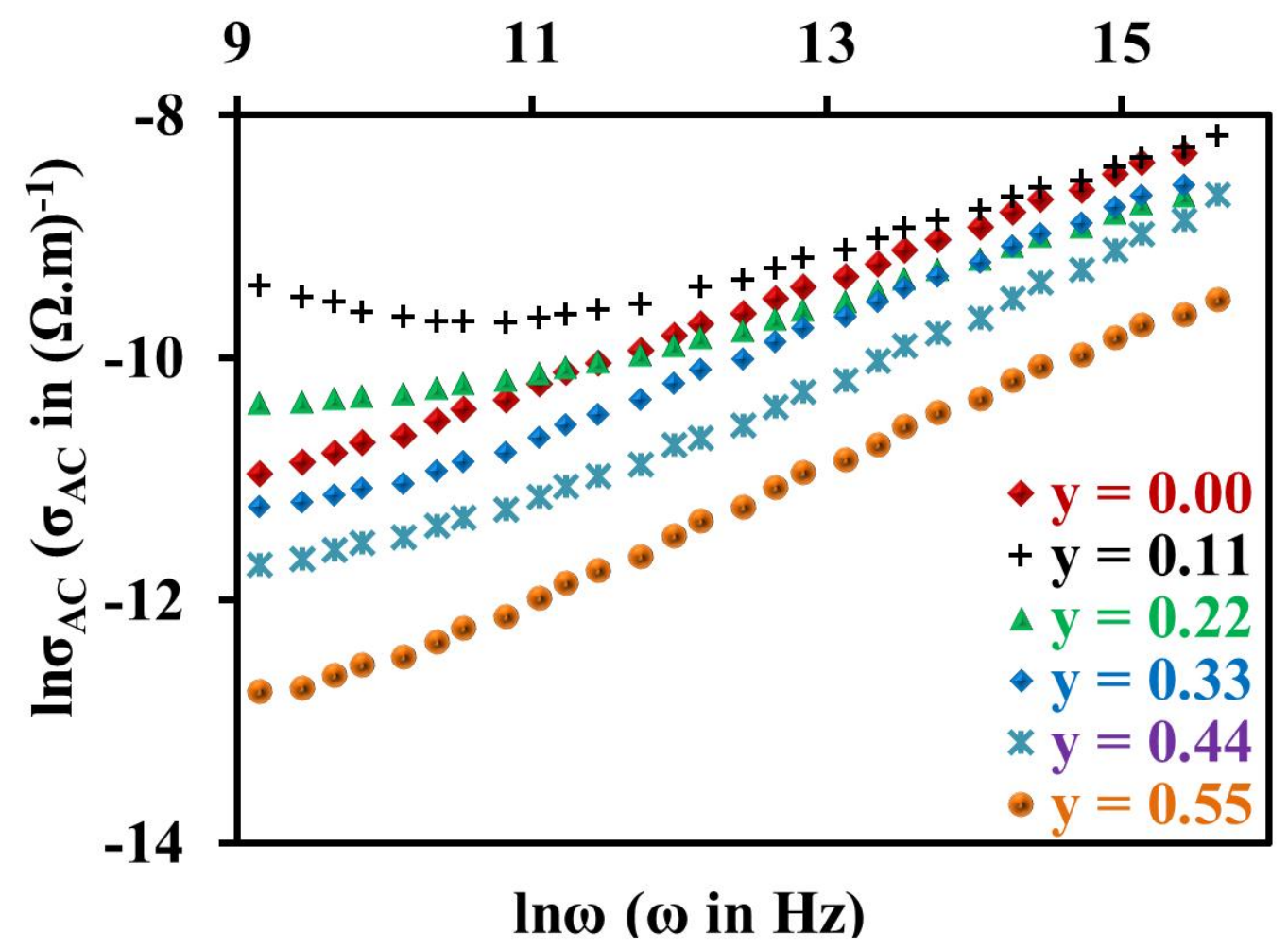

Fig. $9 \ln \sigma \mathrm{AC}$ versus $\ln \omega$ at room temperature for $\mathrm{CoZn}$ ferrite nanoparticles as a function of $\mathrm{Zn}^{2+}$ ions.

Graphs of $\ln \left(\sigma_{\mathrm{AC}}\right)$ and $\ln (\omega)$ for all CoZn ferrite samples have similar trend, where $\sigma_{\mathrm{AC}}$ increases with the increase of $\omega$. Conduction phenomenon is attributed to jumping charge carriers (JCCs) among ions of the element itself existing in different valence states [44]. With respect to cubic crystal lattice of spinel ferrites the most exchange processes of charge carriers (CCs) are occurred at octahedral (B) sites. This because the hopping length between two metal ions on octahedral locations (B) 
smaller than that at tetrahedral locations (A). In addition, because $\mathrm{Fe}^{2+}$ ions prefer occupancy B site so the hopping of charge carriers (CCs) among A sites is not possible [51]. Influence of grain boundaries (GBs) on $\sigma_{\mathrm{AC}}$ is clearer in low frequency range where hopping rate of the charge carriers (CCs) is less and hence $\sigma_{\mathrm{AC}}$ is less too. Where $\omega$ increases the conductive grains become more active according to Maxwell - Wigner model [52]. As a result, the hopping rate of charge carriers (CCs) increases and $\sigma_{\mathrm{AC}}$ increases. In addition, the higher frequencies lead to higher pumping force provided to charge carriers (CCs) so the value of $\sigma_{\mathrm{AC}}$ becomes higher.

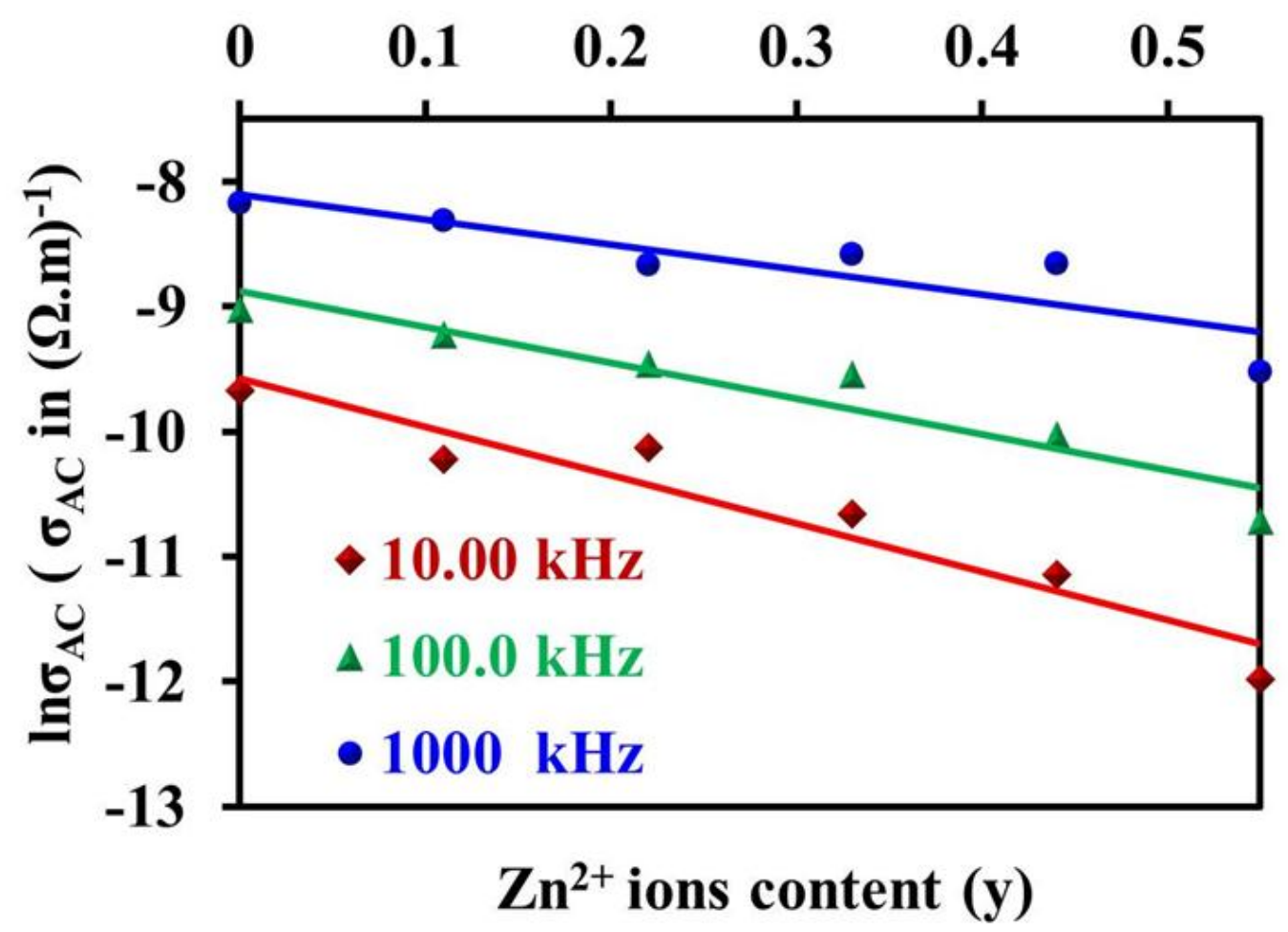

Fig. 10 Fig. 10 AC electrical conductivity of CoZn ferrite nanoparticles versus $\mathrm{Zn}^{2+}$ ions as a function to $(10,100$ and 1000$) \mathrm{kHz}$ frequencies.

Fig. 10 shows the effect of $\mathrm{Zn}$ ions content on the $\sigma_{\mathrm{AC}}$ of the fabricated samples. Where $\mathrm{Zn}^{2+}$ ions exist at $\mathrm{A}$ sites and $\mathrm{Co}^{2+}$ and $\mathrm{Fe}^{3+}$ ions exist at both sites $\mathrm{A}$ and $\mathrm{B}$ [31] so, the addition of $\mathrm{Zn}^{2+}$ to $\mathrm{CoFe}_{2} \mathrm{O}_{4}$ at tetrahedral sites causes an 
increase of migrated $\mathrm{Fe}^{3+}$ ions to octahedral site and a simultaneous decreasing $\mathrm{Co}^{2+}$ ions present at the same site so the charge carriers at B sites decrease and hence it can be said the jumping rate of electrons between $\mathrm{Fe}^{2+}$ and $\mathrm{Fe}^{3+}$ ions and the mobility rate of holes between $\mathrm{Co}^{2+}$ and $\mathrm{Co}^{3+}$ ions decrease and as a result $\sigma_{\mathrm{AC}}$ decreases as can be observed [48].

\subsection{Dielectric properties of CoZn ferrite nano-particles}

\section{6a Dielectric constant $(\varepsilon /)$}

The room temperature dielectric constant $\left(\varepsilon^{\prime}\right)$ for CoZn ferrite versus frequency $\omega$ from $100 \mathrm{kHz}$ to $1 \mathrm{MHz}$ as a function of $\mathrm{Zn}^{2+}$ ions is shown in Fig. 11.

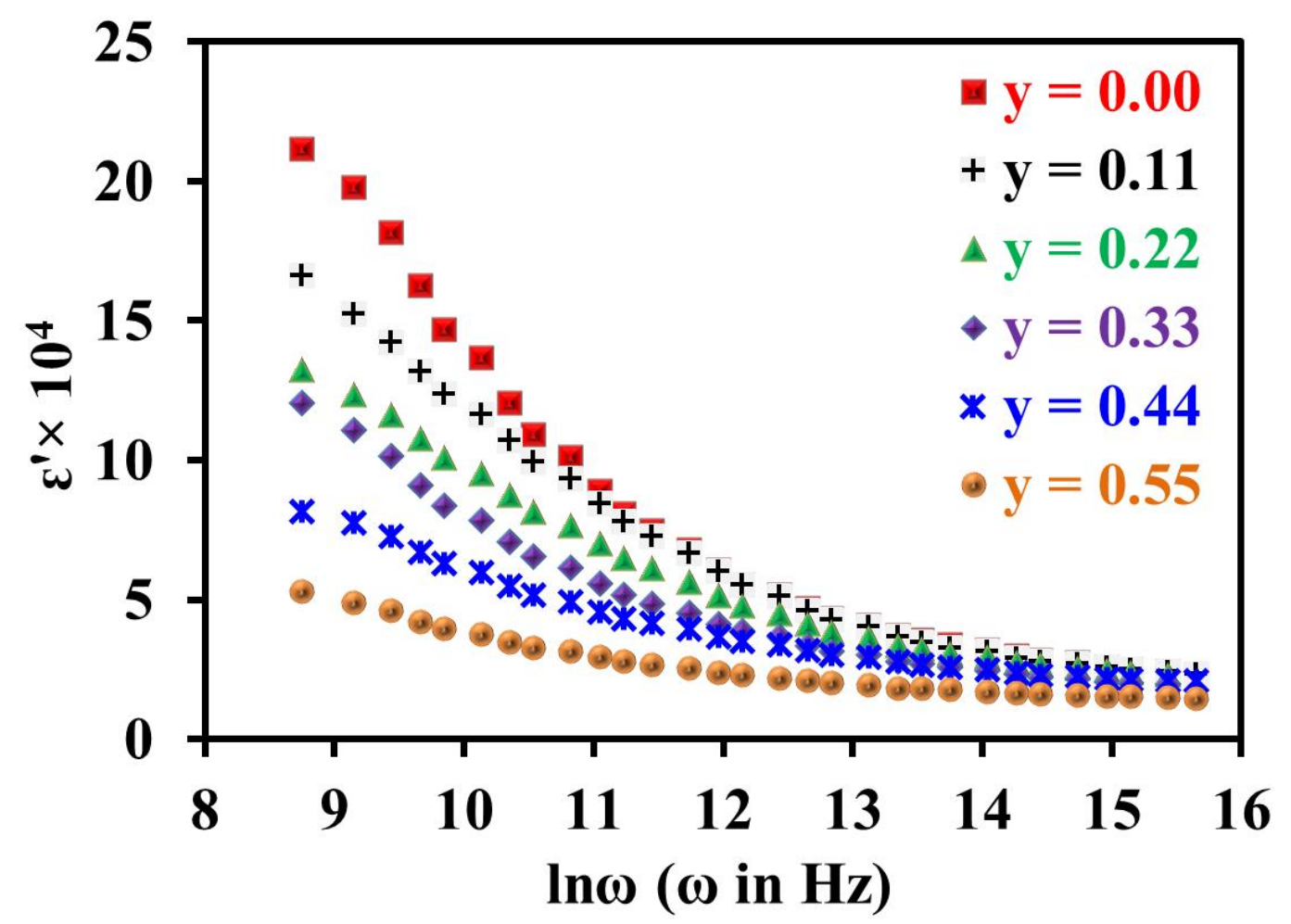

Fig. 11 Dielectric constant of CoZn ferrite nanoparticles versus frequency as a function of $\mathrm{Zn}^{2+}$ ions.

$\varepsilon^{\prime}$ has high values at lower frequency $(\omega)$ and it has lower values at higher $\omega$ where values of $\varepsilon^{\prime}$ decrease with the increase in $\omega$ values and at very high $\omega, \varepsilon^{\prime}$ 
becomes constant this behaviour agrees with earlier study [53]. Koops has proposed that the influence of grains boundaries (GBs) is predominant at lower frequency $(\omega)$ region [54]. GBs work as trap states between valance and conduction bands. Thinner GB means higher $\varepsilon^{\prime}[55]$. The large values of $\varepsilon^{\prime}$ at low $\omega$ are mainly due to the presence of various types of polarization including; space charge, directional, ionic and electronic polarizations. The decrease in $\varepsilon^{\prime}$ with $\omega$ is a natural because any species contributing to polarizability is bound to show lagging behind the external field at higher values [56].

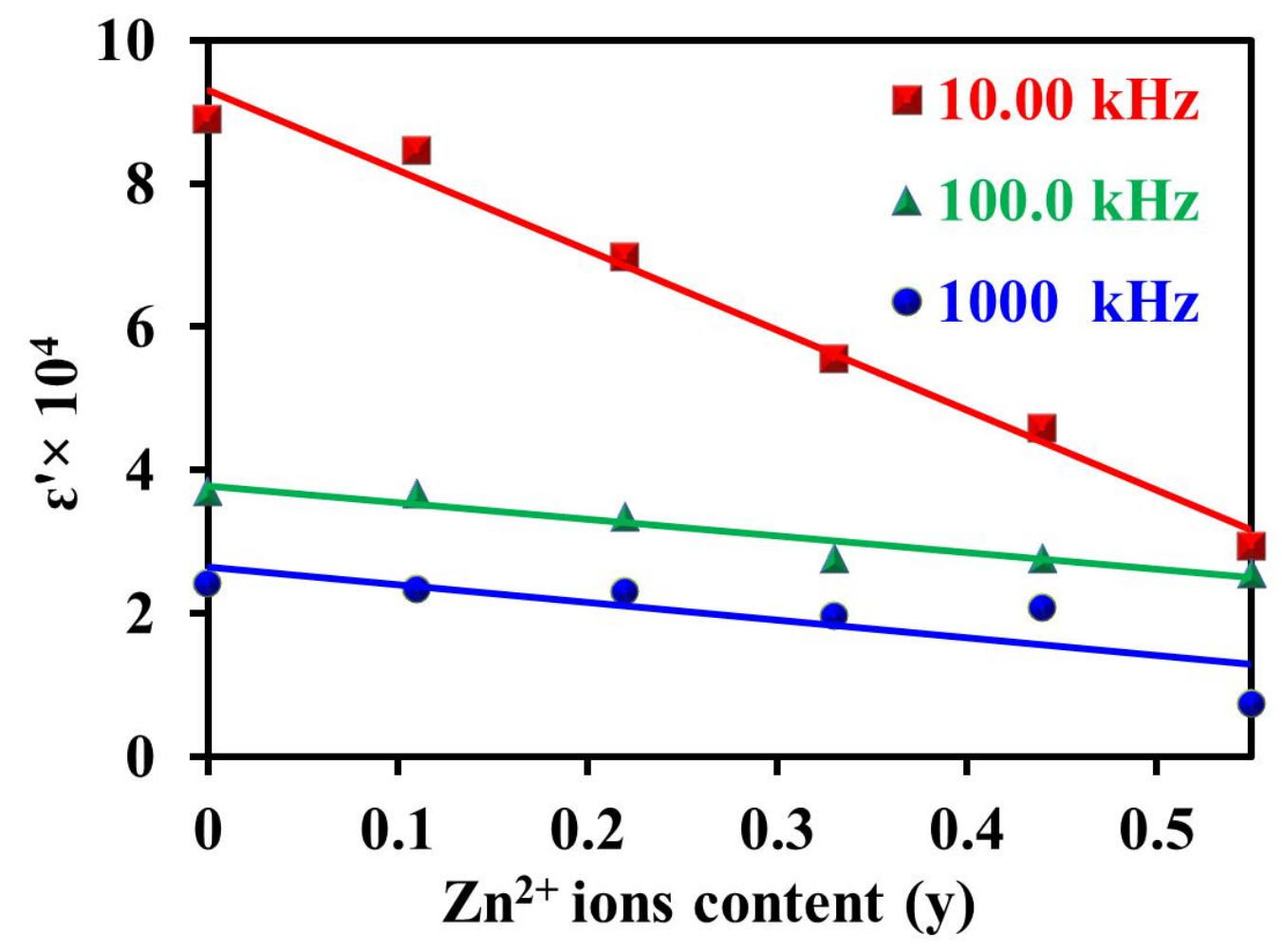

Fig. 12 The dielectric constant ( $(/)$ versus Zn content for the CoZn ferrite nano-particles as a function of frequency.

The transition of charge carriers between cations may leads to the local displacement of electrons in the direction of oscillating field and up to reach a plateau because that above a specific value of $\omega$ the jumping charge carriers cannot 
follow the external alternating field. The correlation between $\varepsilon^{\prime}$ and $\mathrm{Zn}^{2+}$ ions for CoZn ferrite is showed in Fig.12.

\section{6b Dielectric loss factor $\left(\varepsilon^{\prime \prime}\right)$}

The dielectric loss factor $\left(\varepsilon^{\prime /}\right)$ is considered to be the most important part of the total core loss in ferrites [57]. $\varepsilon^{\prime \prime}$ measured how much amount of energy has been dissipated with the external ac electrical field [58]. $\varepsilon^{\prime /}$ in ferrites mainly originates from electron hopping and defect dipoles [59]. Fig. 13 shows the variation of $\varepsilon^{\prime \prime}$ of fabricated CoZn ferrite as a function of $\omega$ from $100 \mathrm{kHz}$ to $1 \mathrm{MHz}$ at $300 \mathrm{k}$. From

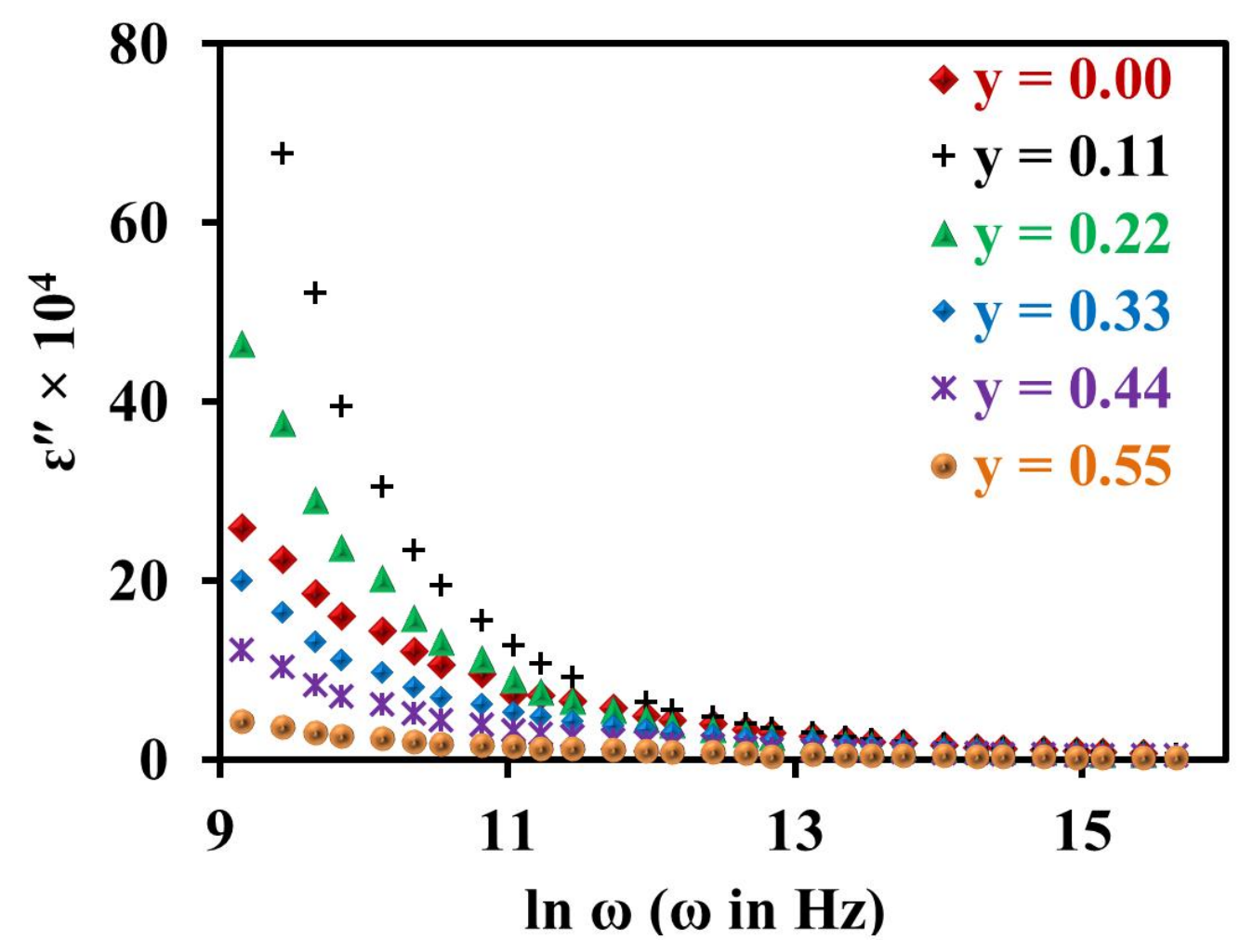

Fig. 13 Dielectric loss factor of CoZn ferrite nanoparticles versus frequency as a function of $\mathrm{Zn}^{2+}$ ions.

Fig. 13 it can be seen that $\varepsilon^{\prime \prime}$ has the same trend of $\varepsilon^{\prime}$. The electron hopping contributes to $\varepsilon^{\prime \prime}$ only in low frequency region. The hopping processes decrease with 
the increase in $\omega$ and hence $\varepsilon^{/ /}$decreases in a high frequency region for each sample as illustrated in Fig. 13. The decrease in $\varepsilon^{\prime \prime}$ with the increase in $\omega$ is attributed to the fact that the hopping of charge carriers cannot follow the changes of the externally applied electric field beyond a certain limit [60].

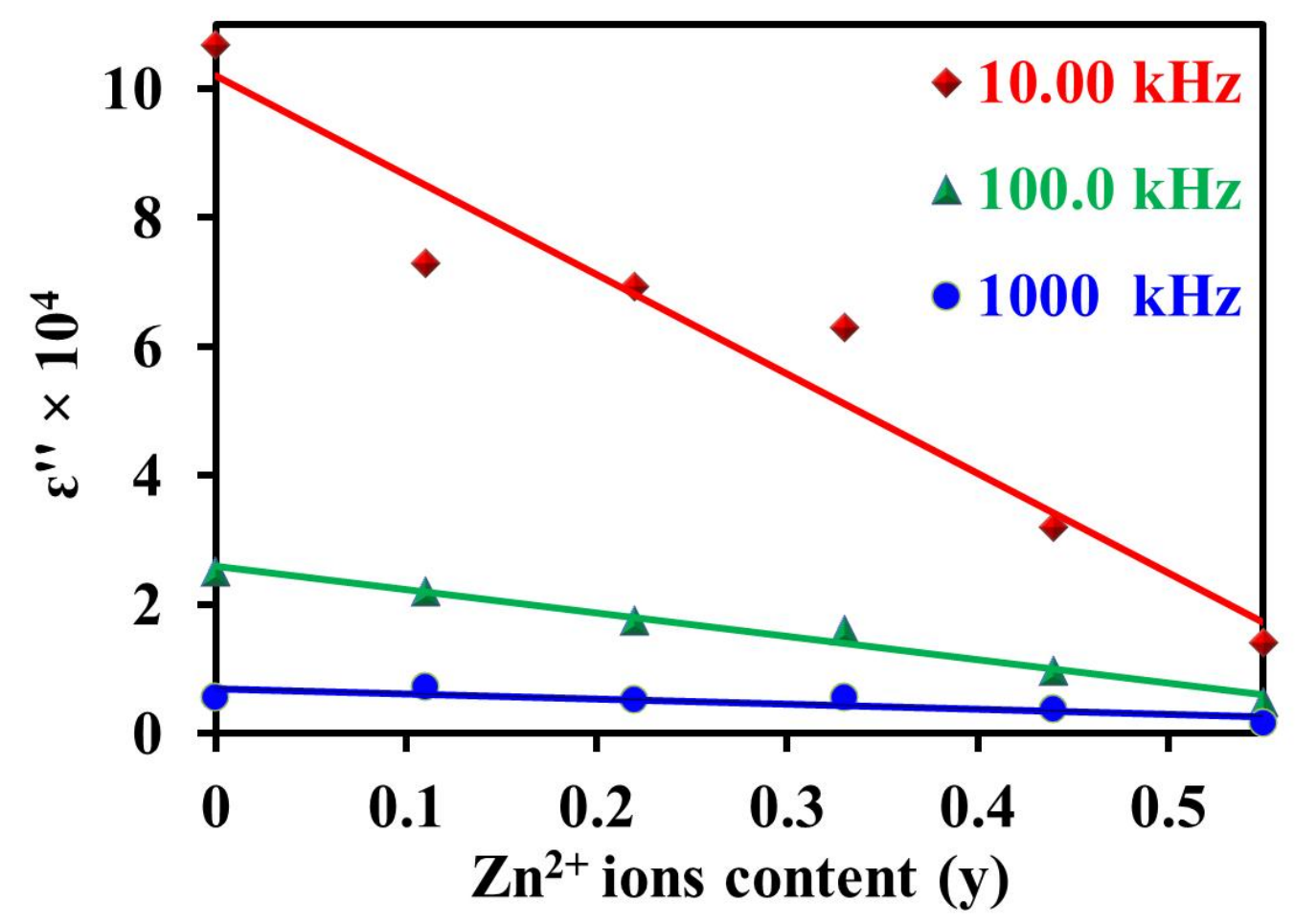

Fig. 14 The dielectric loss $(\varepsilon / /)$ versus $\mathrm{Zn} 2+$ ions for CoZn ferrite nanoparticles as a function to $(10,100$ and 1000$) \mathrm{kHz}$ frequencies.

Fig. 14 shows the variation in $\varepsilon^{\prime \prime}$ of CoZn ferrite series as a function of $\mathrm{Zn}^{2+}$ ions content (y). The decrease in hopping electrons with the increase in $\mathrm{Zn}^{2+}$ ions causing a decrease in electric polarization and a decrease in $\varepsilon^{\prime \prime}$ too. $\varepsilon^{\prime /}$ in ferrite are generally reflected in the conductivity measurements where the samples with highly conductivity exhibiting high losses and vice versa. It is noticed that $\sigma_{\mathrm{AC}}$ decreases markedly by the addition of $\mathrm{Zn}$ concentration so $\varepsilon^{\prime /}$ decreases too. 


\subsection{Magnetic properties of CoZn ferrite nano-particles}

Fig. 15 illustrates hysteresis loops (M- H) of CoZn ferrite nano-particles at $300 \mathrm{~K}$. Coercive field $\left(\mathrm{H}_{\mathrm{C}}\right)$, remanence $\left(\mathrm{M}_{\mathrm{r}}\right)$, magnetization at saturation state $\left(\mathrm{M}_{\mathrm{s}}\right)$ and squareness (remanance) ratios $\left(\mathrm{R}=\mathrm{M}_{\mathrm{r}} / \mathrm{M}_{\mathrm{s}}\right)$ of all CoZn ferrite series derived from $\mathrm{M}-\mathrm{H}$ diagrams and plotted in Figs. 16 ( $\mathrm{a}$ and $\mathrm{b}$ ).

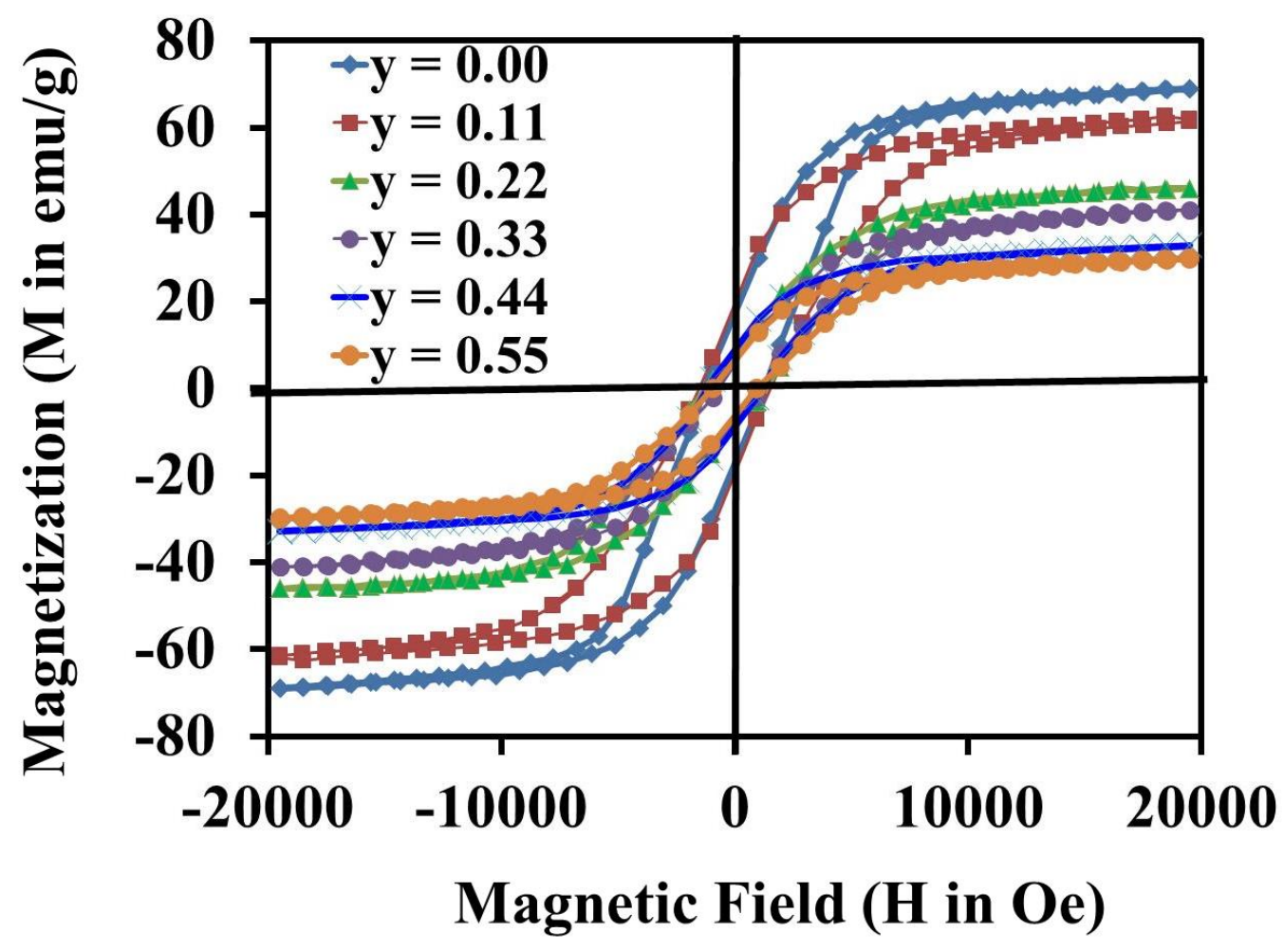

Fig. 15 Magnetic characterization of CoZn ferrite nanoparticles as a function of $\mathrm{Zn}^{2+}$ ions.

Variation of non-magnetic $\mathrm{Zn}^{2+}$ ions in CoZn ferrite series has active effect on their magnetic nature as seen in Figs. 15 and 16. $\mathrm{M}_{\mathrm{r}}$ and $\mathrm{M}_{\mathrm{s}}$ values decrease as nonmagnetic $\mathrm{Zn}^{2+}$ ions increases from the highest points 64 and $18 \mathrm{emu} / \mathrm{g}$ for $\mathrm{CoFe}_{2} \mathrm{O}_{4}$ sample to the lowest point 29 and 6 emu /g for $\mathrm{Co}_{0.45} \mathrm{Zn}_{0.55} \mathrm{Fe}_{2} \mathrm{O}_{4}$ sample respectively as seen in Fig. 16a. 


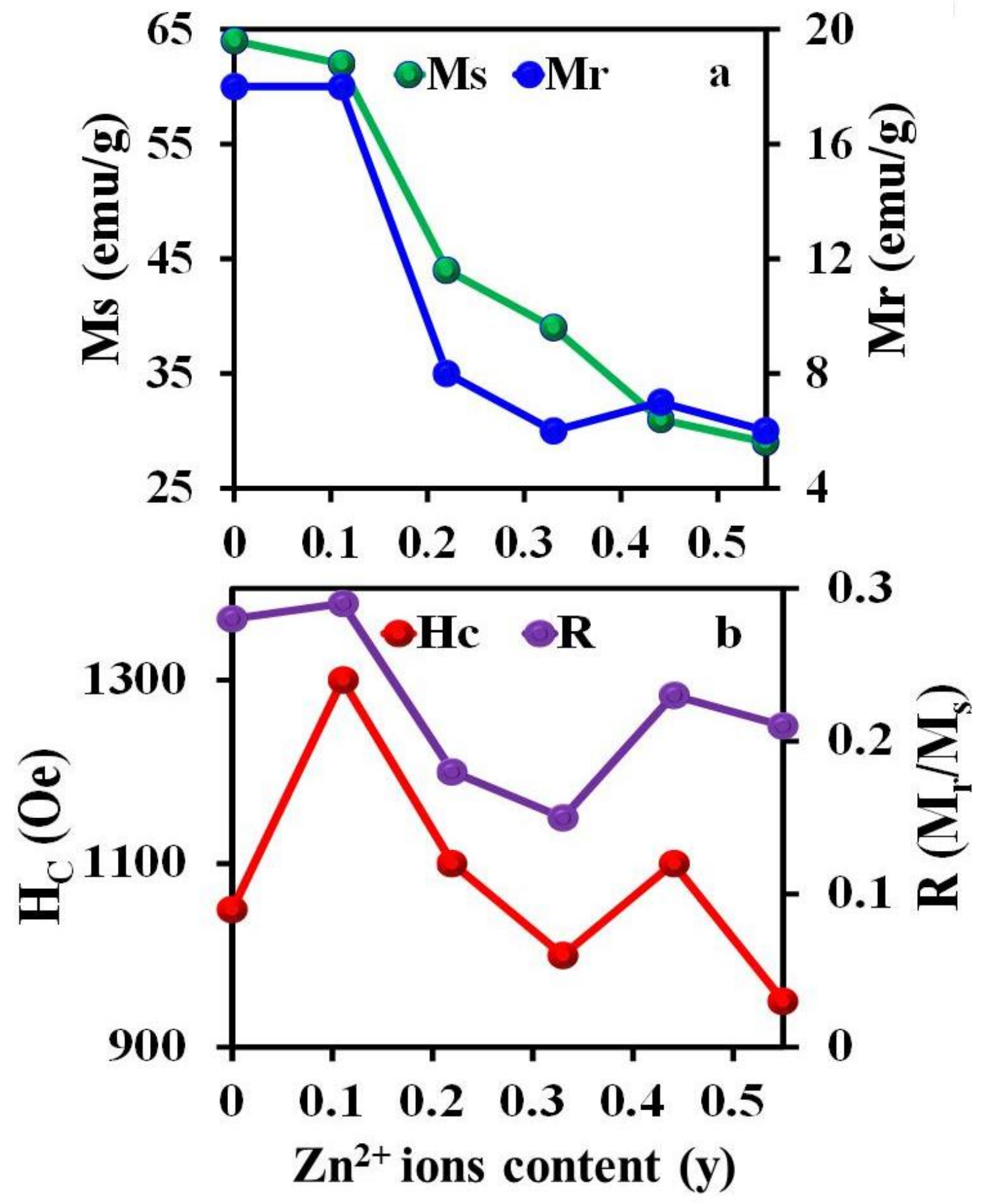

Figs.16 (a, b): a) Remanence and saturation magnetization b) squareness ratio and coercivity of CoZn ferrite nanoparticles as a function of $\mathrm{Zn}^{2+}$ ions. 
That may be retained to the change in crystallite size (D) with non-magnetic $\mathrm{Zn}^{2+}$ ions content (y), where both $\mathrm{M}_{\mathrm{r}}$ and $\mathrm{M}_{\mathrm{s}}$ decrease with increasing crystallite size [61]. CoZn ferrite nano-particles have Ms smaller than that of bulk (80.8 emu/g [62]) due to the contribution of spins of surface particles with respect to core particles, where materials in nano-scales have larger surface per volume ratios which may be leads to surface spin disorder and canting effect [63]. In addition, the investigated CoZn ferrite prepared in ethylene glycol which may be made cover around nano-particles and isolates spines from each other. Role of the surface spins disorder increases (magnetically inactive surface layer) and becomes more efficacious when crystallite size decreases [64], on basis this role of spins disorder, magnetization decreases. Where that CoZn ferrite studied in the nanoscale range, so the variation in magnetization in this case is due to; the distribution of cations at $\mathrm{A}$ and $\mathrm{B}$ locations and ferromagnetic behavior of cobalt ions with compared to the diamagnetic behavior of zinc ions. Coercivities decrease with increasing non-magnetic $\mathrm{Zn}^{2+}$ ions in CoZn ferrite nanoparticles as illustrated from Fig 16 b, this character may be due to smaller magnetic anisotropy of non-magnetic $\mathrm{Zn}^{2+}$ as a compared with magnetic $\mathrm{Co}^{2+}[65]$. From Fig. $16 \mathrm{~b}$ observed that the squareness ratios $\mathrm{R}$ of all $\mathrm{CoZn}$ ferrite are lower than 0.5 which means that interactions between the particles are by magneto-statically and they have multi domain structure [66].

Magnetic anisotropy constant $(\mathrm{K})$ of the samples calculated using $K=M_{S} H_{C} / 0.98$ [67]. The correlation between $K$ of CoZn ferrite samples and $\mathrm{Zn}^{2+}$ ions content is plotted in Fig 17a. Fig. 17a tells that $K$ decreases with increasing $\mathrm{Zn}^{2+}$ ions content (y). The weak $\mathrm{K}$ of cobalt ferrite doped with $\mathrm{Zn}^{2+}$ ions samples is primarily due to decreasing $\mathrm{Co}^{2+}$ ions concentrations. The magnetic moment $\left(\mathrm{n}_{\mathrm{B}}\right)$ calculated experimentally using $n_{B}=\frac{M_{S} M}{5585}$ relation [68], where $\mathrm{M}$ is the molecular weight of ferrite compound sample. 

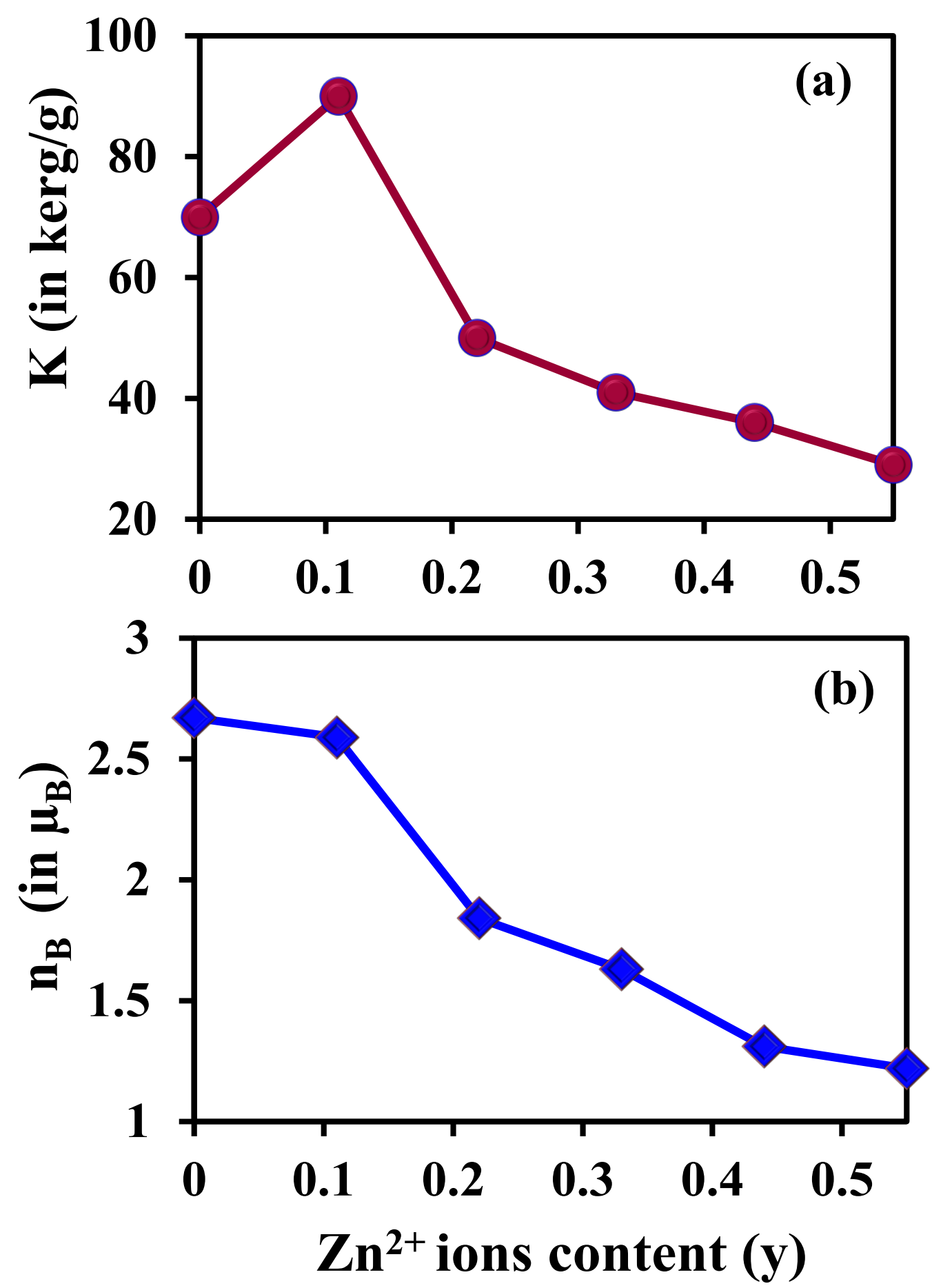

Figs.17 (a, b): a) Magnetic anisotropy constant and b) magnetic moments of $\mathrm{CoZn}$ ferrite as a function of $\mathrm{Zn}^{2+}$ ions. 
Fig. $17 \mathrm{~b}$ shows values of $\mathrm{n}_{\mathrm{B}}$ versus non-magnetic $\mathrm{Zn}^{2+}$ ions of all $\mathrm{CoZn}$ ferrite samples. It observed from Fig. $17 \mathrm{~b}$ that values of $\mathrm{n}_{\mathrm{B}}$ of CoZn ferrite decrease (in general) with increasing non-magnetic $\mathrm{Zn}^{2+}$ ions content (y). As it known structure of cobalt spinel ferrite contains two interstitial sites (A) an octahedral (B) which occupied by cations $\mathrm{Zn}^{2+}, \mathrm{Co}^{2+}$ and $\mathrm{Fe}^{3+}$. The net $\mathrm{n}_{\mathrm{B}}$ values are proportional to difference magnetic moments between $\mathrm{A}$ and $\mathrm{B}$ sits. Where that $\mathrm{Zn}^{2+}, \mathrm{Co}^{2+}$ and $\mathrm{Fe}^{3+}$ ions with $\mathrm{n}_{\mathrm{B}}$ per ion are $0 \mu_{\mathrm{B}}, 3 \mu_{\mathrm{B}}$ and $5 \mu_{\mathrm{B}}[69,70]$ respectively. Addition $\mathrm{Zn}^{2+}$ ions $\left(0 \mu_{\mathrm{B}}\right)$ to $\mathrm{CoFe}_{2} \mathrm{O}_{4}$ at $\mathrm{A}$ sites leads to migrate some $\mathrm{Fe}^{3+}$ ions $\left(5 \mu_{\mathrm{B}}\right)$ to $\mathrm{B}$ sites and this may be leads to decrease the net $\mathrm{n}_{\mathrm{B}}$ between $\mathrm{A}$ and $\mathrm{B}$ sites decreases.

\subsection{Optical properties of CoZn nanoferro-fluid}

Optical data used to calculate the energy gap $\left(E_{g}\right)$ of CoZn ferrite. The optical absorbance spectra of CoZn nanoferro-fluid studied from 200 to $800 \mathrm{~nm}$ using UvVis spectrophotometer as illustrated in Fig. 18 which further used for $E_{g}$ calculation. The data analyzed by the relation: $\alpha h v=A\left(h v-E_{g}\right)^{n / 2}$ [24] for near edge absorption. hv is the energy of incident photon, $\alpha$ is the absorbance coefficient, $\mathrm{A}$ is a constant and $\mathrm{n}$ is a number equal to one for direct and indirect optical gap respectively. The value of direct energy gap $E_{g}$ calculated by extrapolating the straight-line portion of graph on $\mathrm{h} v$ axis as clarified in Fig. 19. The produced $\mathrm{E}_{\mathrm{g}}$ for CoZn ferrite nano-particles is listed in Table 2. From Table 2 it can be observed that by increasing concentration of $\mathrm{Zn}^{2+}$ ions, value of $\mathrm{Eg}$ decreases. It has been noticed that there is significant decrease in $\mathrm{E}_{\mathrm{g}}$ with $\mathrm{Zn}^{2+}$ ions which is may be due to increasing the crystallite size [68]. As the crystallite size increases the valance and conduction bands become closer and narrowing $\mathrm{E}_{\mathrm{g}}$. 


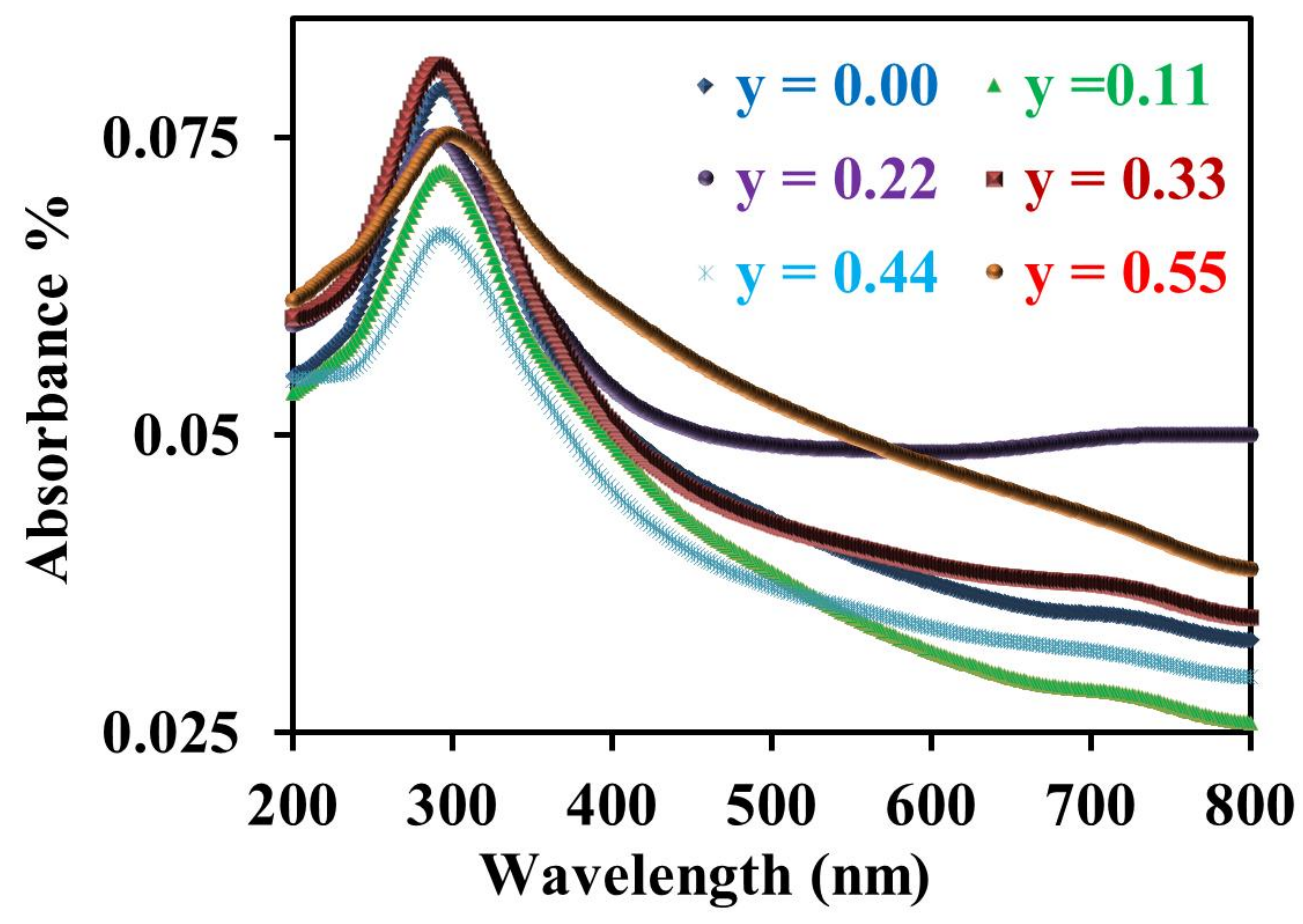

Fig. 18 The absorbance spectra of ferrofluid based on CoZn ferrite nanoparticles samples as a function of $\mathrm{Zn}^{2+}$ ions.

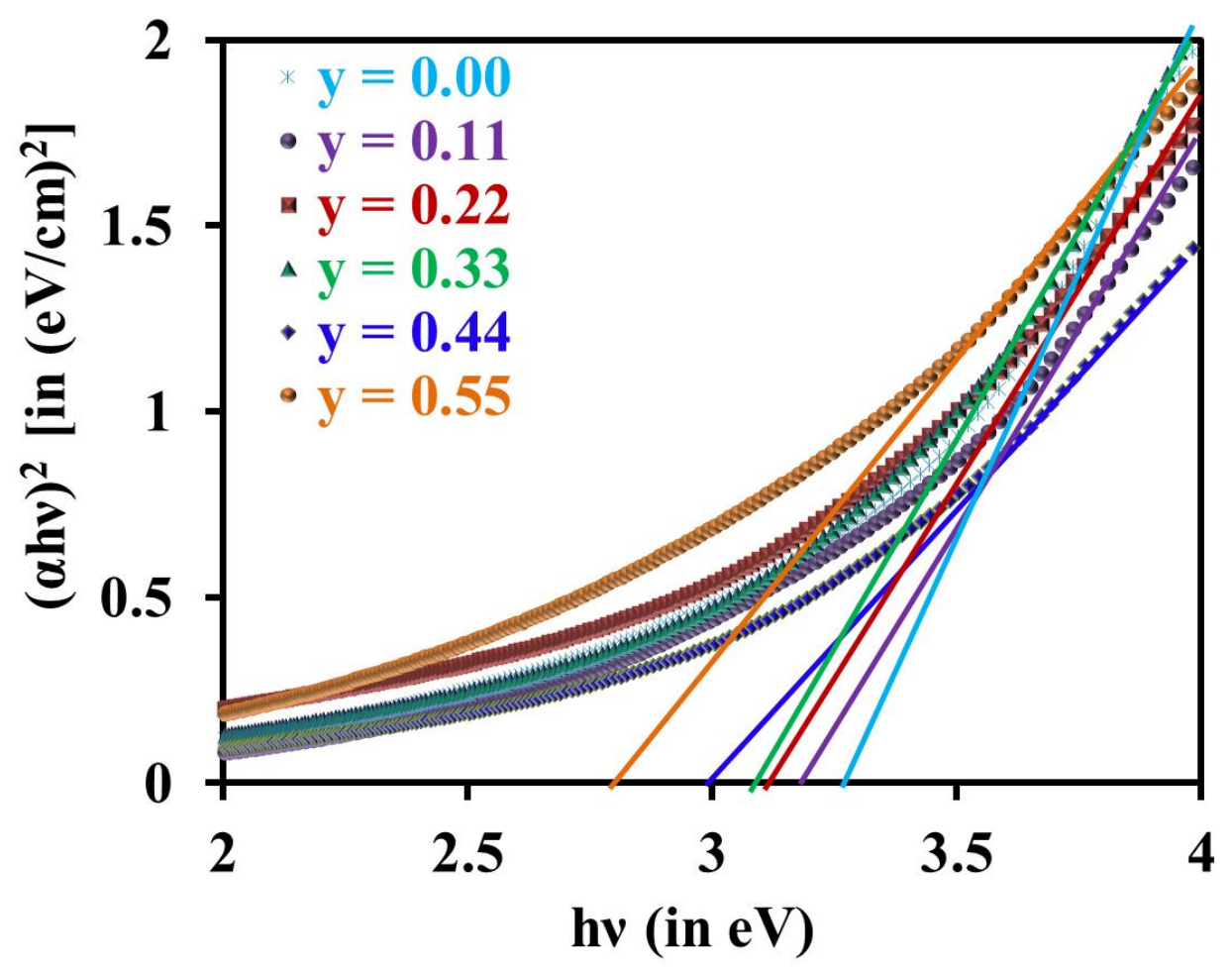


Fig. $19(\alpha v h)^{2}$ versus photon energy (hv) of ferrofluid based on CoZn ferrite nanoparticles samples as a function of $\mathrm{Zn}^{2+}$ ions.

\section{Conclusion}

CoZn ferrites nanoparticles synthesized by modified inverse co-precipitation technique. The X-ray patterns of all the synthesized samples were confirmed to have unique spinel phase structure without evidence of impurities. The average lattice constant, the average crystallite size and the X-ray density increase from 8.399 to $8.412 \AA$, from 32.33 to $52.87 \mathrm{~nm}$ and from 5.26 to $5.31 \mathrm{~g} / \mathrm{cm}^{3}$ respectively with the increase in $\mathrm{Zn}^{2+}$ ions in the range $(0.00-0.55)$. SEM images show that all the fabricated samples have nanosize grains with a nearly homogeneous size and the grain size increase with the increase of $\mathrm{Zn}$ substitution. There is a blue shift in the energy optical band gap of CoZn ferrite nanoparticles with decreasing the crystallite size. $M_{r}$ and $M_{s}$ values vary from the maximum values 64 and $18 \mathrm{emu} / \mathrm{g}$ for the sample with $\mathrm{y}=0.00$ to the minimum values 29 and $6 \mathrm{emu} / \mathrm{g}$ for the sample with $\mathrm{y}$ $=0.55$ respectively. AC electrical conductivity increases with the increase of a frequency and it decreases with the increase of $\mathrm{Zn}$ content. The values of dielectric constant and dielectric loss factor have very high value at lower frequencies. $\mathrm{Co}_{0.45} \mathrm{Zn}_{0.55} \mathrm{Fe}_{2} \mathrm{O}_{4}$ has the largest value of resistivity and lowest value of dielectric loss factor so this sample is might be suitable for high-frequency and microwave applications.

\section{References}

[1] Na Dong, Fangzhen He, Junlian Xin, Qizhao Wang, Ziqiang Lei nn, Bitao Su, Materials Letters 141 (2015) 238-241. doi:10.1016/j.matlet.2014.11.054 
[2] M. Vadivel, R. Ramesh Babu, K. Ramamurthi, M. Arivanandhan, Journal of Physics and Chemistry of Solids 102 (2017) 1-11. doi:10.1016/j.jpcs.2016.10.014

[3] Jie Ma, Jiantao Zhao, Wenlie Li, Shuping Zhang, Zhenran Tian, Sergey Basov, Materials Research Bulletin 48 (2013) 214-217. doi:10.1016/j.materresbull.2012.09.072

[4] Anderson, R.M.; Vestal, C.R.; Samia, A.C.S.; Zhang, Z.J. Appl. Phys. Lett. (2004), 84(16), 3115-3117. doi:10.1063/1.1712031

[5] G. Baldi, D. Bonacchi, M.C. Franchini, D. Gentili, G. Lorenzi, A. Ricci, C. Ravagli, Langmuir 23 (2007) 4026-4028. doi:10.1021/la063255k

[6] M. Veverka, P. Veverka, O. Kaman, A. Lanc`ok, K. Za've`ta, E. Pollert, K. Kni'ž̌ek, J. Boha’ ček, M. Beneš, P. Kšapar, E. Duguet, S. Vasseur, Nanotechnology 18 (2007)345704. doi:10.1088/0957-4484/18/34/345704

[7] J. J. Versluijs, M. A. Bari, J. M. D. Coey, Physical Review Letters,87(2)(2001)26601- 26604. doi:10.1103/PhysRevLett.87.026601 [8] V. Pillai, D.O. Shah, Journal of Magnetism and Magnetic Materials 163 (1996) 243-248. doi:10.1016/S0304-8853(96)00280-6

[9] M. Fang, V. Strom, R.T. Olsson, L. Belova, K. Rao, Applied Physics Letters, 99(22)(2011)222501-222503. doi:10.1063/1.3662965 
[10] Thanasak Sathitwitayakul, Maxim V. Kuznetsov, Ivan P. Parkin, Russell Binions, Materials Letters 75 (2012)36-38. doi:10.1016/j.matlet.2012.02.003

[11] Amal S. Hathout, Abdulhadi Aljawish, Bassem A. Sabry, Aziza A. ElNekeety, Mohamed H. Roby, Nasseralla M. Deraz, Soher E. Aly, Mosaad Abdel-Wahhab, Journal of Applied Pharmaceutical Science 7 (01)(2017)086092. doi:10.7324/JAPS.2017.70111

[12] M. Artus, L. Ben Tahar, F. Herbst, L. Smiri, F. Villain, N. Yaacoub, J.M. Grene` che, S. Ammar, F. Fie' vet, J. Phys.: Condens. Matter 23 (2011) 506001. doi:10.1088/0953-8984/23/50/506001

[13] R Skomski, Nanomagnetics , J. Phys.: Condens. Matter 15(20)(2003)R841 R896. doi:10.1088/0953-8984/15/20/202

[14] A. Manikandan, L.J. Kennedy, M. Bououdina, J.J. Vijaya, J. Magn. Magn. Mater. 349(2014) 249-258. doi:10.1016/j.jmmm.2013.09.013

[15] C. Singh, S. Jauhar, V. Kumar, J. Singh, S. Singhal, Mater. Chem. Phys. 156 (2015) 188- 197. doi:10.1016/j.matchemphys.2015.02.046

[16] S.K. Chang, Z. Zainal, K.B. Tan, N.A. Yusof, W.M.D. Wan Yusoff, S.R. S. Prabaharan, Int. J. Energ. Res. 39 (2015) 1366-1377. doi:10.1002/er.3339

[17] I.C. Nlebedim, M. Vinitha, P.J. Praveen, D. Das, D.C. Jiles, Temperature dependence of the structural, magnetic, and Phys. 113 (2013)193904. 
doi:10.1063/1.4804963

[18] X.G. Huang, J. Zhang, S.R. Xiao, G.S. Chen, J. Am. Ceram. Soc. 97 (2014)1363-1366. doi:10.1111/jace.12909

[19] X.F. Yang, Q. Jin, Z.P. Chen, Q.L. Li, B. Liu, J. Magn. Magn. Mater. 367(2014) 64-68. 10. doi:1016/j.jmmm.2014.04.053

[20] S.B. Waje, M. Hashim, W.D.W. Yusoff, Z. Abbas, J. Magn. Magn. Mater. 322 (2010) 686-691. doi:10.1016/j.jmmm.2009.10.041

[21] M. Ajmal, N.A. Shah, A. Maqsooda, M.S. Awan, M. Arif, J. Alloys Comp. 508 (2010) 226-232. doi:10.1016/j.jallcom.2010.08.067

[22] R.S. Yadav, J. Havlica, M. Hnatko, P. Šajgalík, C. Alexander, M. Palou, E. Bartoníc`ková, M. Bohác``, F. Frajkorová, J. Masilko, M. Zmrzly’ , L. Kalina, M. Hajdúchová, V. Enev, J. Magn. Magn. Mater.378(2015)190-199.

[23] Y. Koseoglu, A. Baykal, F. Gozuak, H. Kavas, Polyhedron 28 (2009) 28872892. doi:10.1016/j.poly.2009.06.061

[24] R. M. Kershi, F. M. Ali, M. A. Sayed; Journal of Advanced Ceramics 7(3)(2018)218-228. doi:10.1007/s40145-018-0273-5

[25] Jianhua Liu, Dun You, Mei Yu, Songmei Li, Materials Letters 65 (2011) 929932. doi:10.1016/j.matlet.2010.10.070

[26] Md. T. Rahman, M. Vargas, C.V. Ramana, Journal of Alloys and Compounds 
617 (2014) 547-562. doi:10.1016/j.jallcom.2014.07.182

[27] Raghvendra Singh Yadav, Ivo Kuritka, Jarmila Vilcakova, Pavel Urb anek, Michal Machovsky, Milan Masar, Martin Holek, Journal of Physics and Chemistry of Solids 110 (2017) 87-99. doi: 10.1016/j.jpcs.2017.05.029

[28] I. Gul and A. Maqsood, Journal of Alloys and Compounds.,465(2008)227-230. doi:10.1016/j.jallcom.2007.11.006

[29] N. Deraz, Journal of Analytical and Applied Pyrolysis 88 (2010) 103-109. doi:10.1016/j.jaap.2010.03.002

[30] M. A. Ahmed, N. Okasha, R. M. Kershi, ournal of Magnetism and Magnetic Materials 320 (2008) 1146-1150. doi:10.1016/j.jmmm.2007.11.014

[31] S. Singhal, J. Singh, S. Barthwal and K. Chandra, J. Solid State Chem., 178 (2005) 3183-3189. doi: 10.1016/j.jssc.2005.07.020

[32] M. Sertkol, Y. Koseoglu, A.Baykal, H. Kavas, A. Bozkurt, M. Toprak, J. Alloys Comps., 486 (2009) 325-329. doi:10.1016/j.jallcom.2009.06.128

[33] Gagan Dixit, Jitendra Pal Singh, R.C. Srivastava, H.M. Agrawal, Journal of Magnetism and Magnetic Materials 324 (2012) 479 - 483. doi:10.1016/j.jmmm.2011.08.027

[34] Samad Zare, Ali A. Ati, Shadab Dabagh, R.M.Rosnan, Zulkafli Othaman, Journal of Molecular Structure 1089 (2015) 25-31. doi:10.1016/j.molstruc.2015.02.006 
[35] G. Raju, N. Murali, M.S.N.A. Prasad, B. Suresh, D. Apparao Babu, M. Gnana Kiran, A. Ramakrishna, M. Tulu Wegayehu, B. Kishore Babu, Materials Science for Energy Technologies 2 (2019) 78-82. doi:10.1016/j.mset.2018.11.001

[36] Alida Mazzoli, Favoni Orlando, Powder Technol. 225 (2012) 65-71, doi:10.1016/j.powtec.2012.03.033.

[37] Bogdan Dereka, Eric Vauthey, Chem. Sci., 2017, 8, 5057. doi:

$10.1039 / \mathrm{c} 7 \mathrm{sc} 00437 \mathrm{k}$

[38] R. D. Waldron, Phys. Rev.,99 (1955) 1727-1735.

doi:10.1103/PhysRev.99.1727

[39] M.S. Khandekar, R.C. Kambale , J.Y. Patil, Y.D. Kolekar, S.S. Suryavanshi, Journal of Alloys and Compounds 509 (2011) 1861-1865.

doi:10.1016/j.jallcom.2010.10.073

[40] M.M. Mallapur, P.A. Shaikh, R.C. Kambale, H.V. Jamadar, P.U. Mahamuni, B.K. Chougulel, J Alloys Compd.,479(1-2)(2009)797-802. doi:

10.1016/j.jallcom.2009.01.142

[41] S. A. Mazen and N. I. Abu-Elsaad, IR Spectra, ISRN Condensed Matter Physics 2012(2012)1-9. doi:10.5402/2012/907257

[42] K.A. Mohammed, A.D. Al-Rawas, A.M. Gismelseed, A. Sellai, H.M. 
Widatallah, A.Yousif, M.E. Elzain, M. Shongwe. Physica B 407 (2012) 795804. doi:10.1016/j.physb.2011.12.097

[43] H. Sozeri, Z. Durmus, and A. Baykal, Materials Research Bulletin 47 (2012) 2442-2448. doi: 10.1016/j.materresbull.2012.05.036

[44] K. Khalaf, A. Al-Rawas, H. Widatallah, K. Al-Rashdi, A. Sellai, A. Gismelseed, M. Hashim, S. Jameel, M. Al-Ruqeishi, K. Al-Riyami, M. Shongwe, A. Al-Rajhi, J. Alloys Compd., 657 (2016) 733-747. doi:10.1016/j.jallcom.2015.10.157

[45] T. Srinivasan, C. Srivastava, N. Venkataramani, M. Patni, Bulletin of Materials Science 6 (6) (1984) 1063-1067. doi:10.1007/BF02743958

[46] Shahid Hussain, Asghari Maqsood, Journal of Alloys and Compounds 466 (2008) 293-298. doi:10.1016/j.jallcom.2007.11.074

[47] John T. S. Irvine, Alfonso Huanosta, Raul Valenzuela, Anthony R. West, Journal of the American Ceramic Society, 73 (1990) 729-732. doi:10.1111/j.1151-2916. 1990.tb06580.x

[48] Muhammad Tahir Farid, Ishtiaq Ahmad, Muddassra Kanwal, and Irshad Ali, Chinese Journal of Physics55(2017)813-824. doi:10.1016/j.cjph.2017.02.011 [49] Uzma Ghazanfar, S.A. Siddiqi, G. Abbas, Materials Science and Engineering B 118 (2005) 132-134. doi:10.1016/j.mseb.2004.12.086 
[50] David Adler and Julius Feinleib, Phys. Rev.B 2(1970)3112. doi:10.1016/j.mseb.2004.12.086

[51] Maki Okube, Taro Oshiumi, Toshiro Nagase, Ritsuro Miyawaki, Akira Yoshiasa, Satoshi Sasakie, and Kazumasa Sugiyama, J. Synchrotron Rad. (2018). 25, 1694-1702. doi.:10.1107/S1600577518013954

[52] R. Karthik, V. Tummala, Proceedings 4 (2017)8751-8757. doi.org/10.1016/j.matpr.2017.07.224

[53] M. Abdullah Dar, Khalid Mujasam Batoo, Vivek Verma, W.A. Siddiqui, R.K. Kotnala, Journal of Alloys and Compounds 493 (2010) 553-560. doi:10.1016/j.jallcom.2009.12.154

[54] C. G. Koops, Phys Rev,83(1951)121-124. doi:10.1103/PhysRev.83.121

[55] D. Kothari, S. Phanjoubam, J. Baijal, Journal of Materials Science25 (1990) 5142-5146. doi:10.1007/BF00580142

[56] I.H. Gul, A. Maqsood, Journal of Alloys and Compounds., 465 (2008) 227231. doi:10.1016/j.jallcom.2007.11.006

[57] R.V Mangalaraja, S Ananthakumar, P Manohar, F.D Gnanam, Journal of Magnetism and Magnetic Materials 253(2002) 56-64. doi:10.1016/S03048853(02)00413-4 
[58] S. O. Nelson, Journal of Food Engineering., 21(1994) 365-384.

doi:10.1016/0260-8774(94)90080-9

[59] Huma Malik, Azhar Mahmood, Khalid Mahmood, Maria Yousaf Lodhi

Muhammad Farooq Warsi, Imran Shakir, Hassan Wahab, M. Asghar,

Muhammad Azhar Khan, Ceramics International 40 (2014) 9439-944.

doi:10.1016/j.ceramint.2014.02.015

[60] Vithal Vinayak, Pankaj P. Khirade, Shankar D. Birajdar, R. C. Alange, K.

M. Jadhav, Journal of Superconductivity and Novel Magnetism 28(11)

(2015) 3351-3356. doi:10.1007/s10948-015-3159-6

[61] Sonal Singhal, Sheenu Jauhar, Jagdish Singh, Kailash Chandra, Sandeep

Bansal, J. Mol. Struct.,1012(2012)182-188.

doi:10.1016/j.molstruc.2011.12.035

[62] M. Grigorova, H. J. Blythe, V. Blaskov, V. Rusanov, V. Petkov, V. Masheva,

D. Nihtianova, L. M. Martinez, J. S. Muñoz, M. Mikhov, J. Magn. Magn.

Mater., 183(1998)163-172. doi:10.1016/S0304-8853(97)01031-7

[63] M.A. Ait Kerroum, A. Essyedb, C. Iacovitad, W. Baaziza, D. Ihiawakrima, O. Mounkachib, M. Hamedoune, A. Benyoussefb,e,f, M. Benaissab, O. Ersen, Journal of Magnetism and Magnetic Materials 478 (2019) 239-246. doi:10.1016/j.jmmm.2019.01.081 
[64] Hamid Ghayour, Majid Abdellahi, Mazyar Ghadiri Nejad, Amirsalar Khandan, Saeed Saber-Samandar, J Aust Ceram Soc (2017). doi: 10.1007/s41779-017$0144-5$

[65] M. Sundararajan, L. John Kennedy, J. Judith Vijay, Udaya Aruldos, Spectrochimica Acta Part A: Molecular and Biomolecular Spectroscopy, 140(2015) 421-430. doi: 10.1016/j.saa.2014.12.035

[66] E Adrian R. Muxworthy, Wyn Williams, JOURNAL OF GEOPHYSICAL RESEARCH, 111(2006)1-6. doi:10.1029/2006JB004588

[67] Syed Ismail Ahmad, Shakeel Ahmed Ansari, D. Ravi Kumar, Materials Chemistry and Physics, 208(2018) 248-257. doi:10.1016/j.matchemphys.2018.01.050

[68] Shraddha Agrawal, Azra Parveen, Ameer Azam, Journal of Magnetism and Magnetic Materials 414 (2016) 144-152. doi:10.1016/j.jmmm.2016.04.059

[69] Y.Y. Meng, Z.W. Liu, H.C. Dai, H.Y. Yu, D.C. Zeng, S. Shukla, R.V. Ramanujan Powder Technology, 229(2012) 70-275. doi: 10.1016/j.powtec.2012.06.050

[70] M.A. Ahmed, N. Okasha, R.M. Kershi, Physica B 405 (2010) 3223-3233. doi.10.1016/j.physb.2010.04.047 
Figures

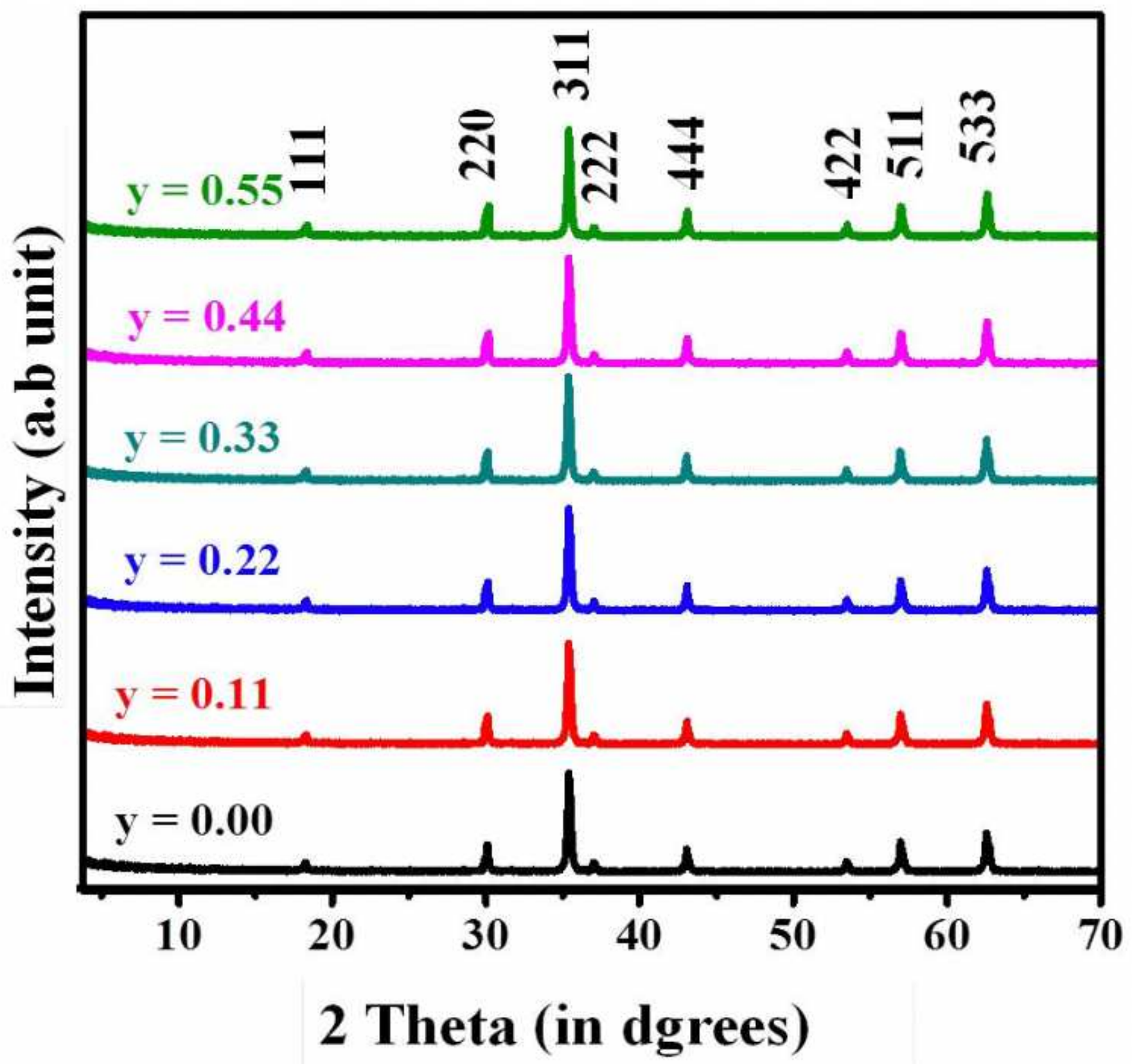

Figure 1

XRD Pattern of CoZn ferrite nanoparticles as a function of Zn2+ ions. 


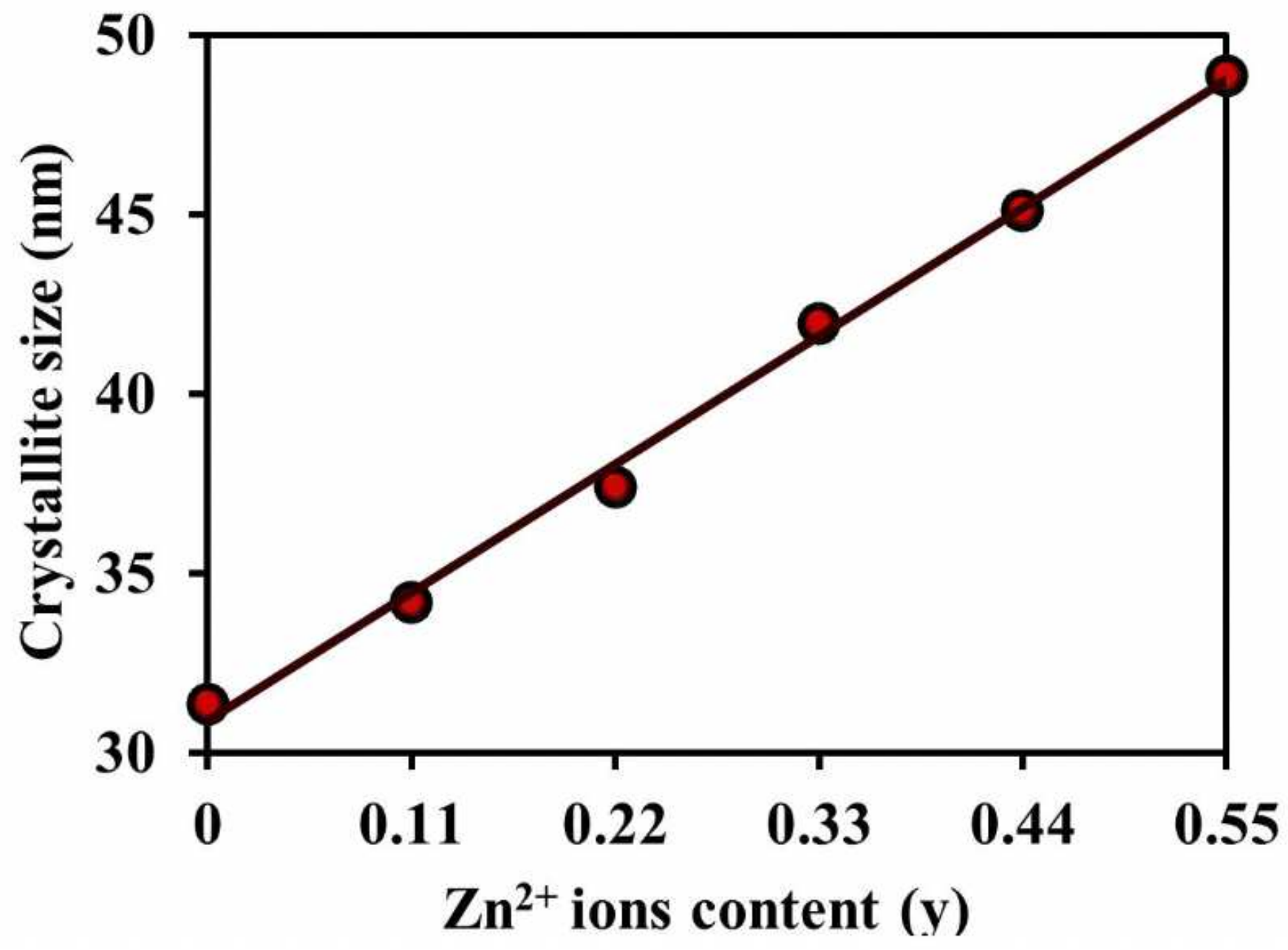

Figure 2

The average crystallite size of CoZn ferrite nanoparticles as a function of $\mathrm{Zn} 2+$ ions.

政

Figure 3

SEM images and particles distribution (inset) of CoZn ferrite nanoparticles as a function of $\mathrm{Zn} 2+$ ions. 


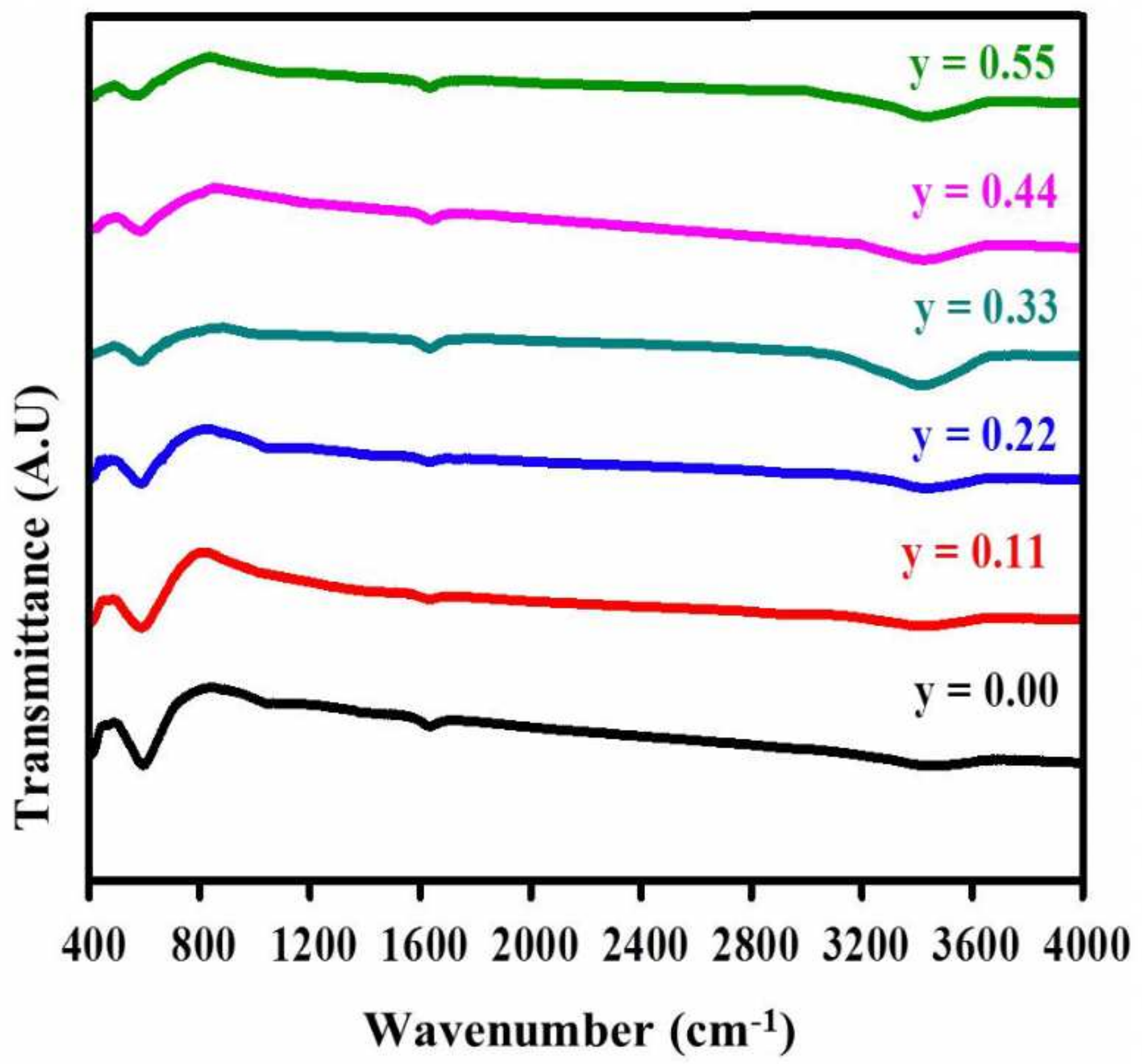

Figure 4

FTIR spectra of CoZn ferrite nanoparticles as a function of Zn2+ ions. 


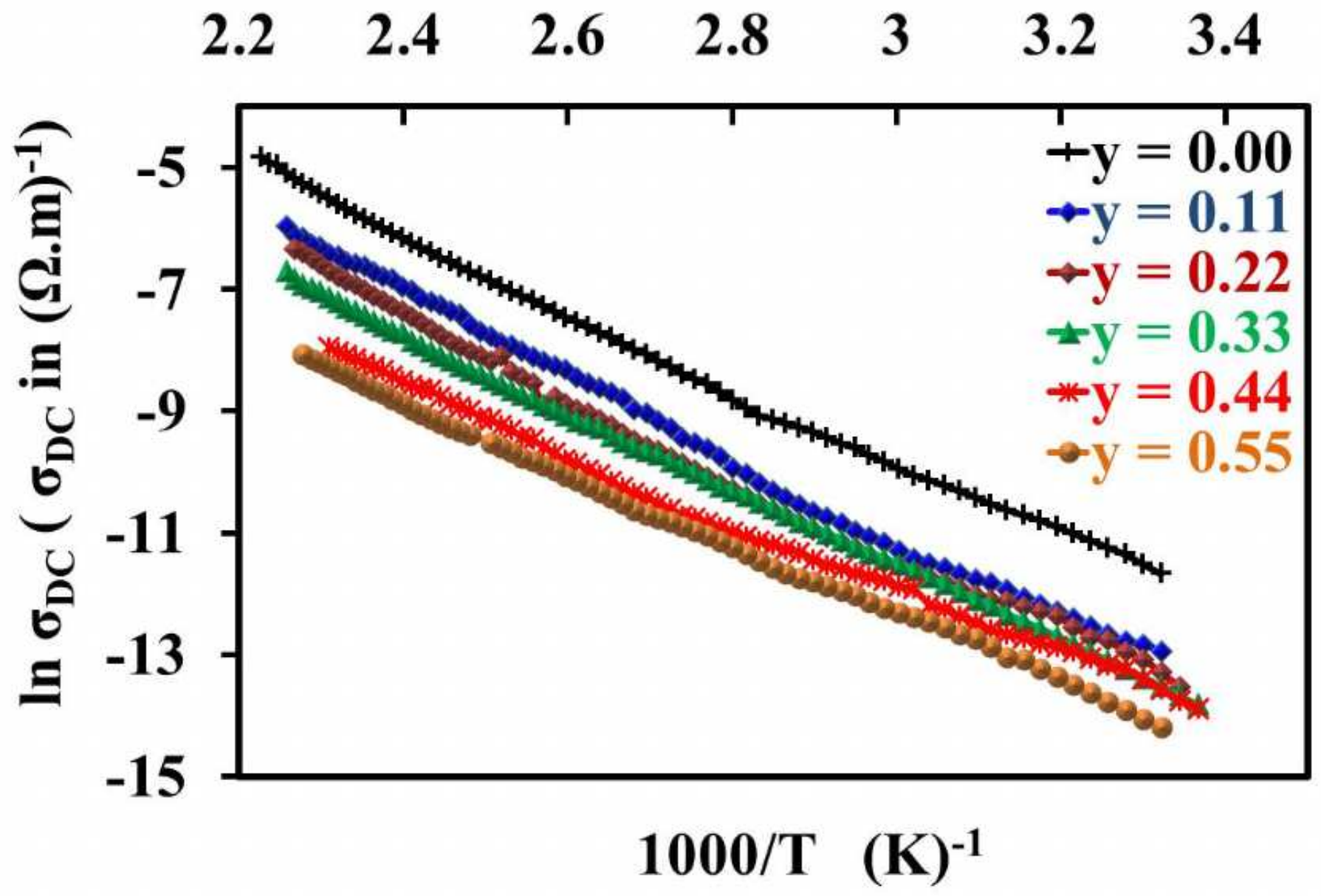

Figure 5

The temperature dependent DC electrical conductivity of CoZn ferrite nanoparticles as a function of Zn2+ ions. 


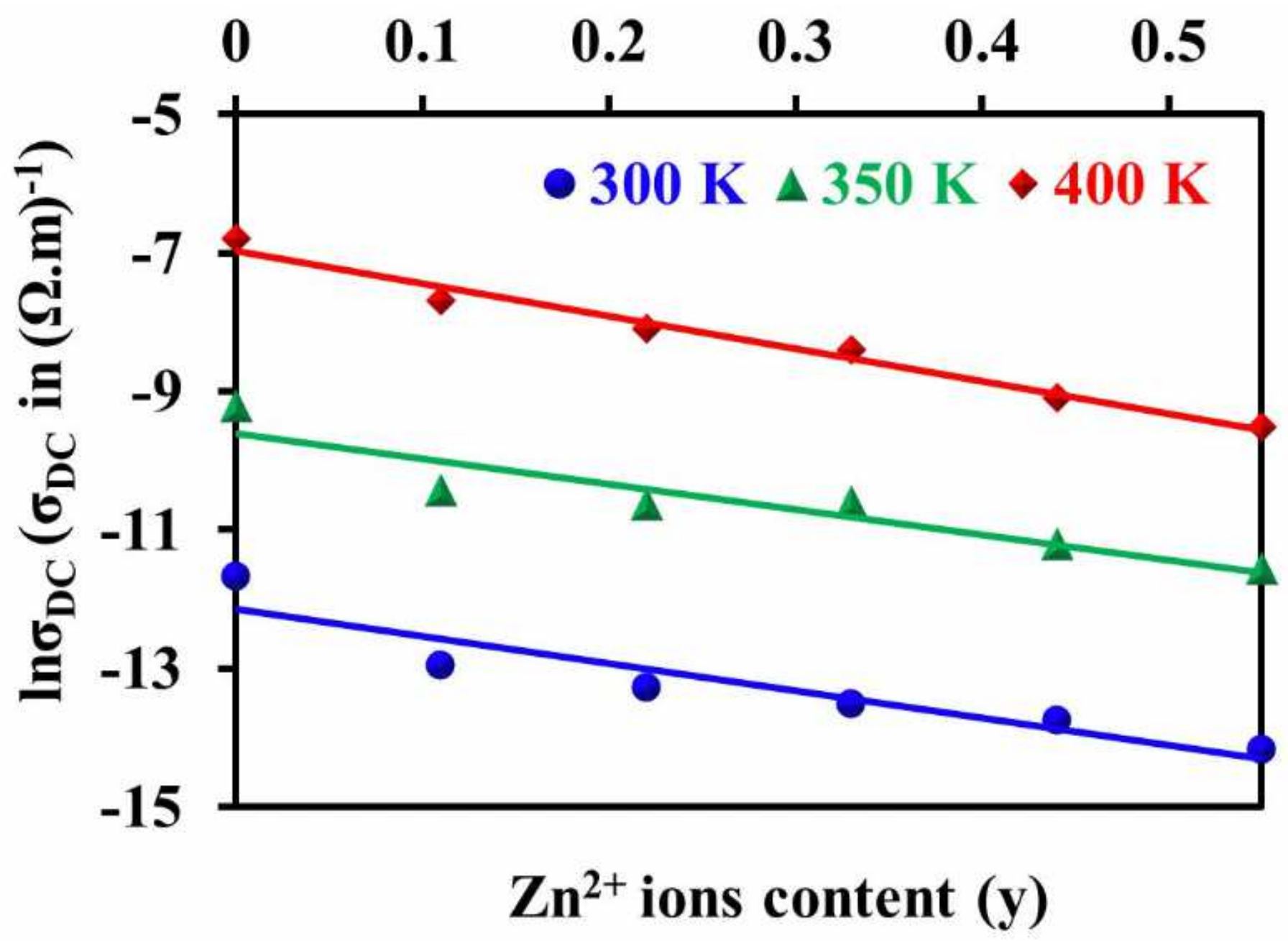

Figure 6

DC electrical conductivity of CoZn ferrite nanoparticles versus $\mathrm{Zn} 2+$ ions as a function of temperature $(\mathrm{K})$. 


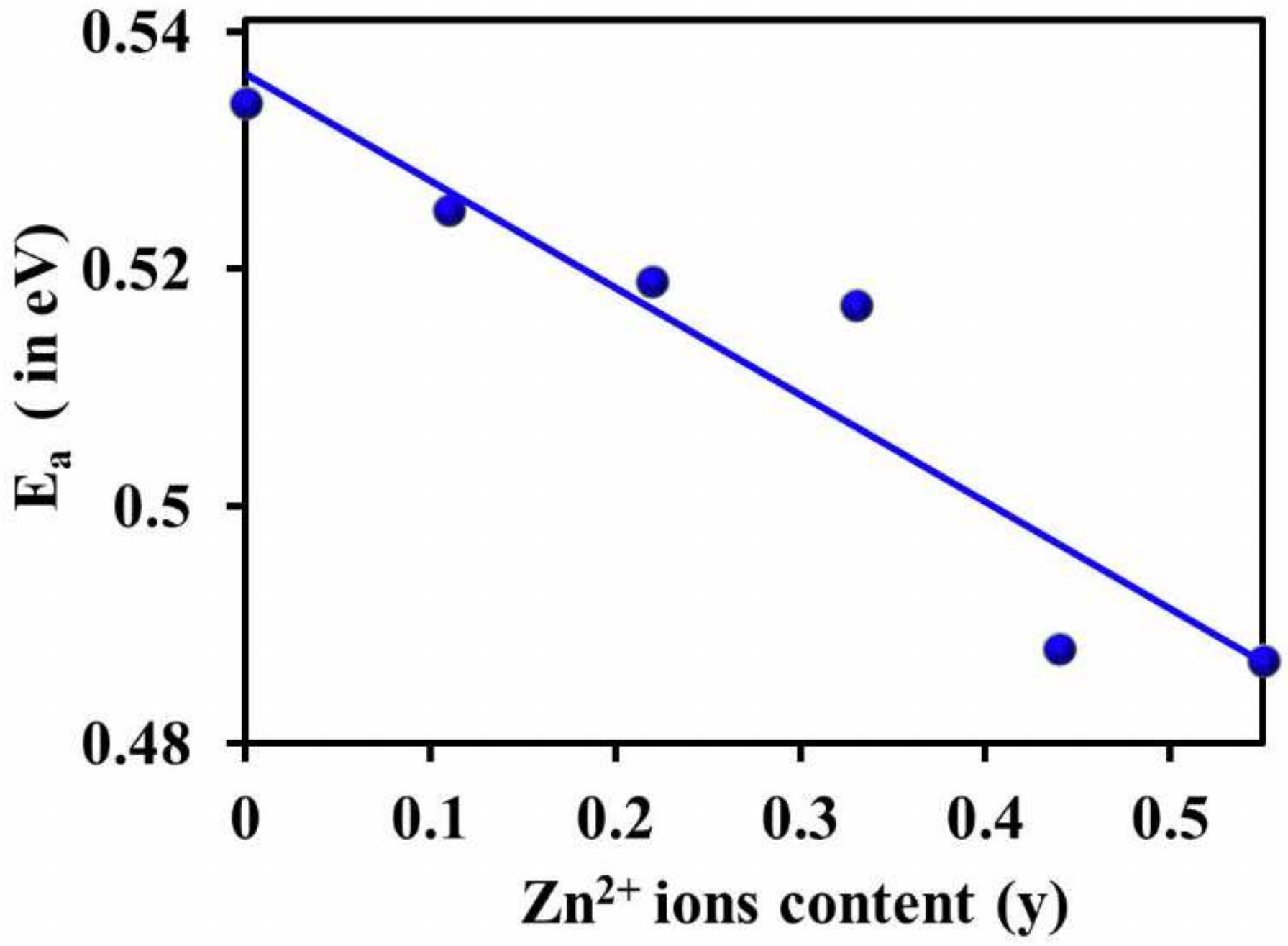

Figure 7

Activation energy of CoZn ferrite nanoparticles as a function of $\mathrm{Zn} 2+$ ions. 


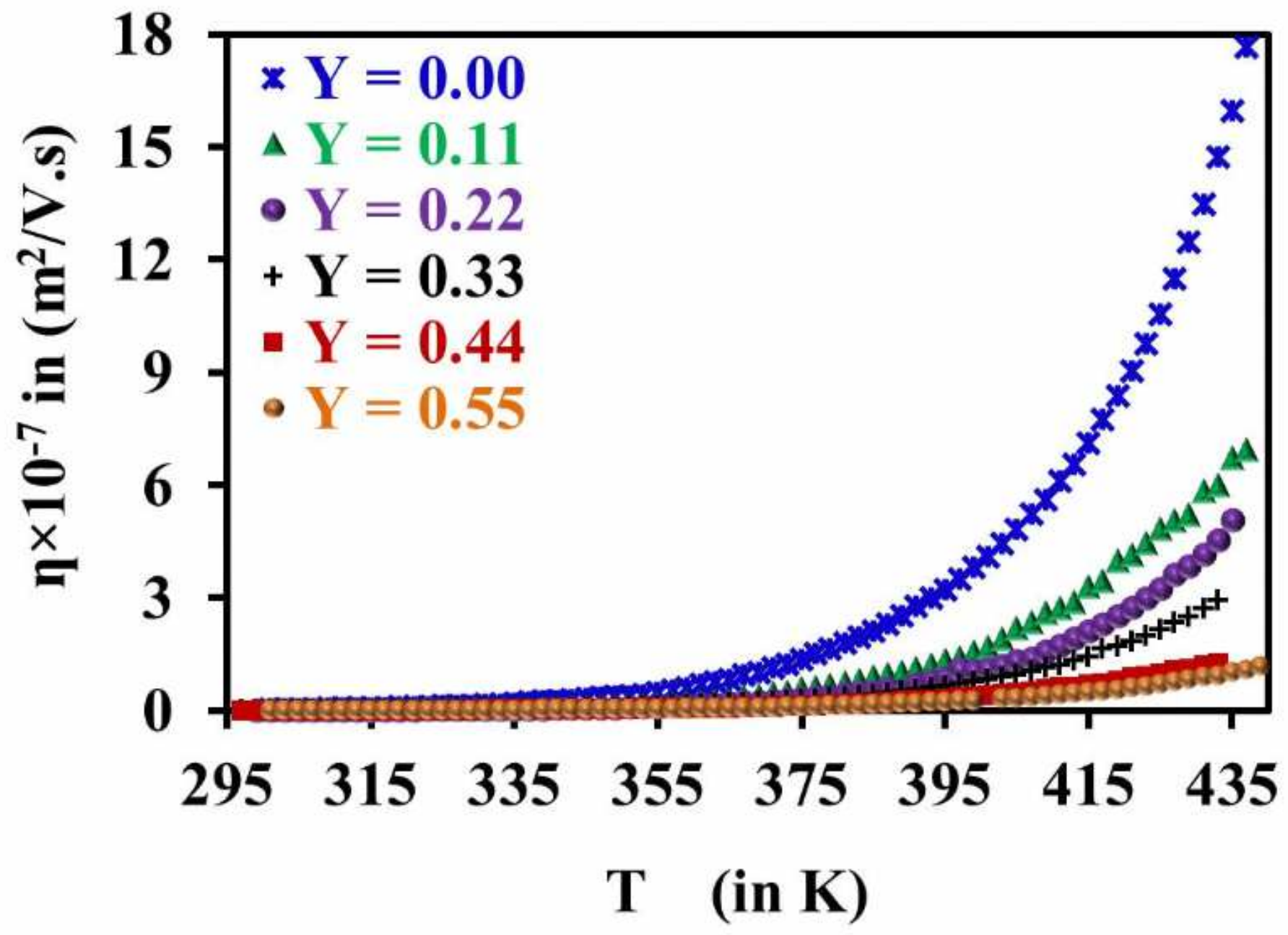

Figure 8

The temperature dependent DC mobility of CoZn ferrite nanoparticles as a function of $\mathrm{Zn} 2+$ ions. 


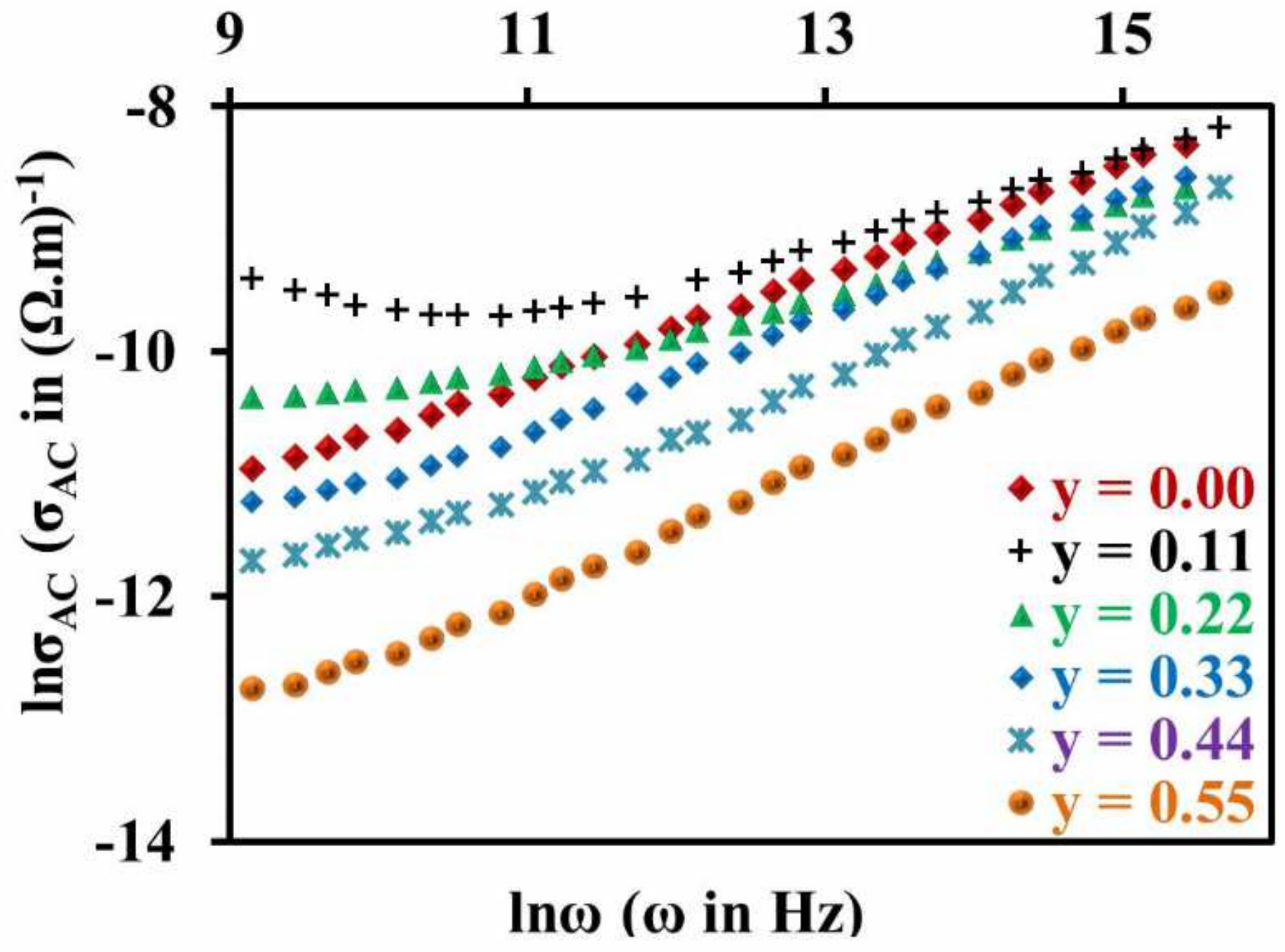

Figure 9

In $\sigma A C$ versus In $\omega$ at room temperature for CoZn ferrite nanoparticles as a function of $\mathrm{Zn} 2+$ ions. 


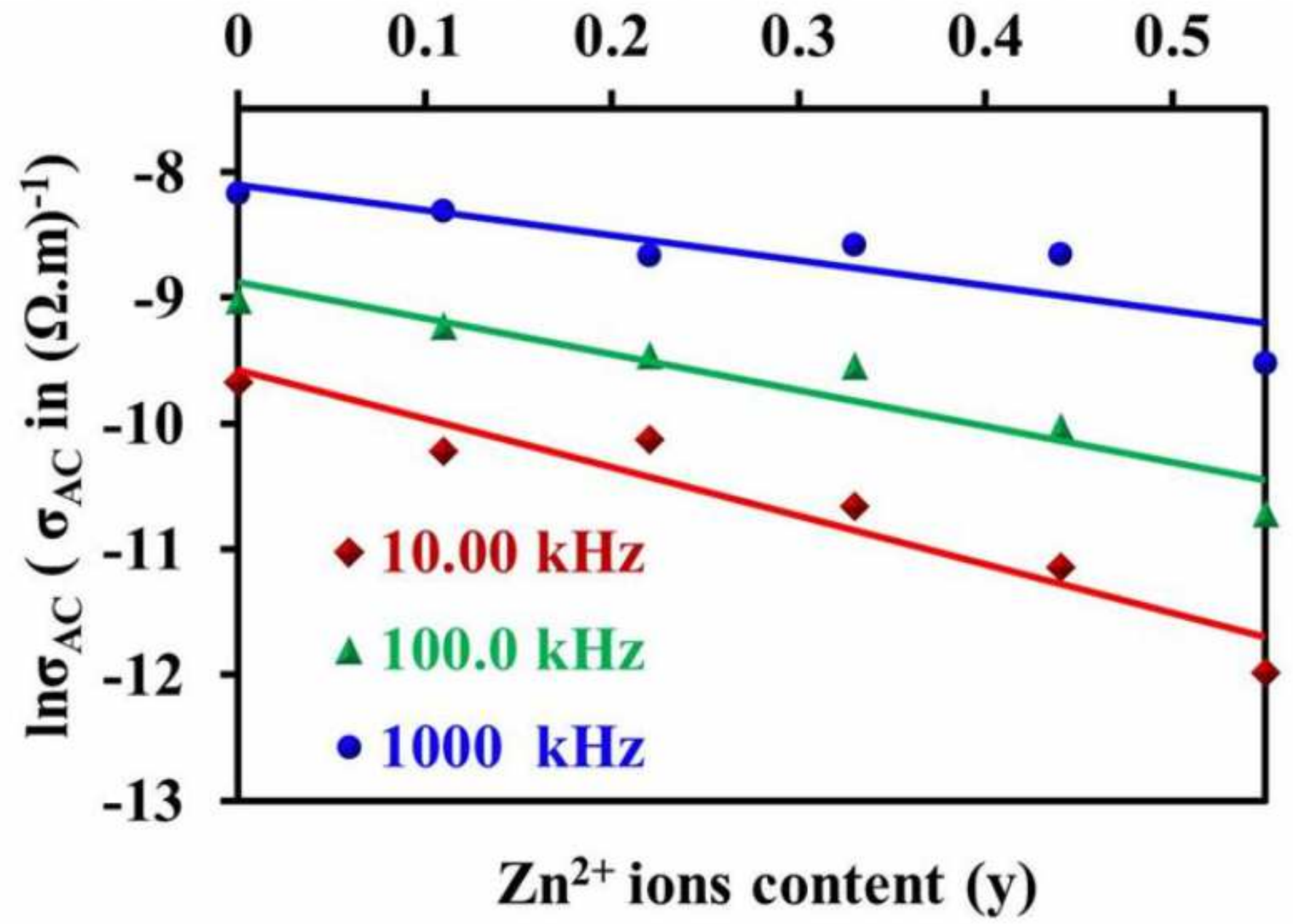

Figure 10

AC electrical conductivity of CoZn ferrite nanoparticles versus $Z n 2+$ ions as a function to $(10,100$ and 1000) $\mathrm{kHz}$ frequencies. 


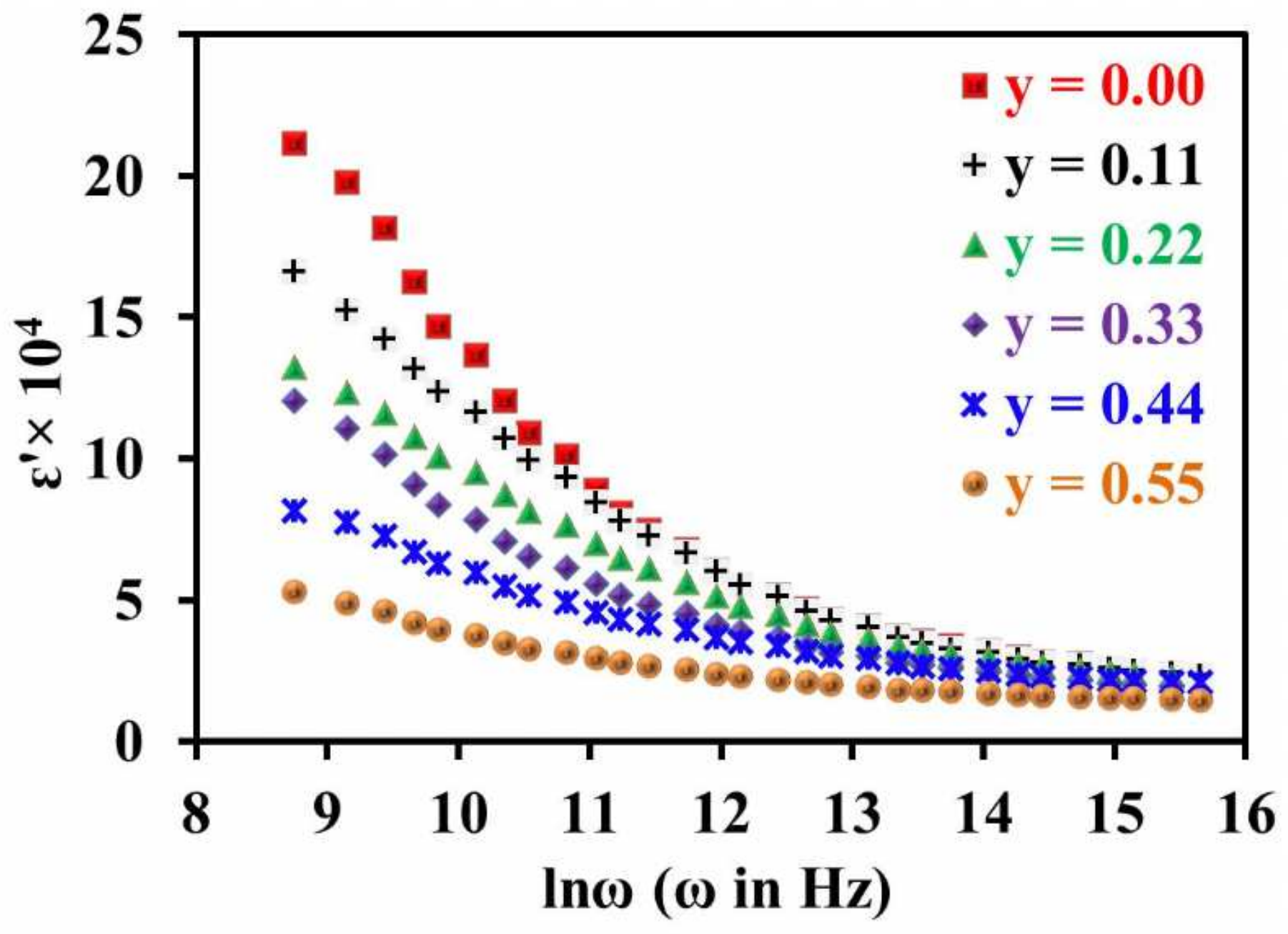

Figure 11

Dielectric constant of CoZn ferrite nanoparticles versus frequency as a function of $\mathrm{Zn} 2+$ ions. 


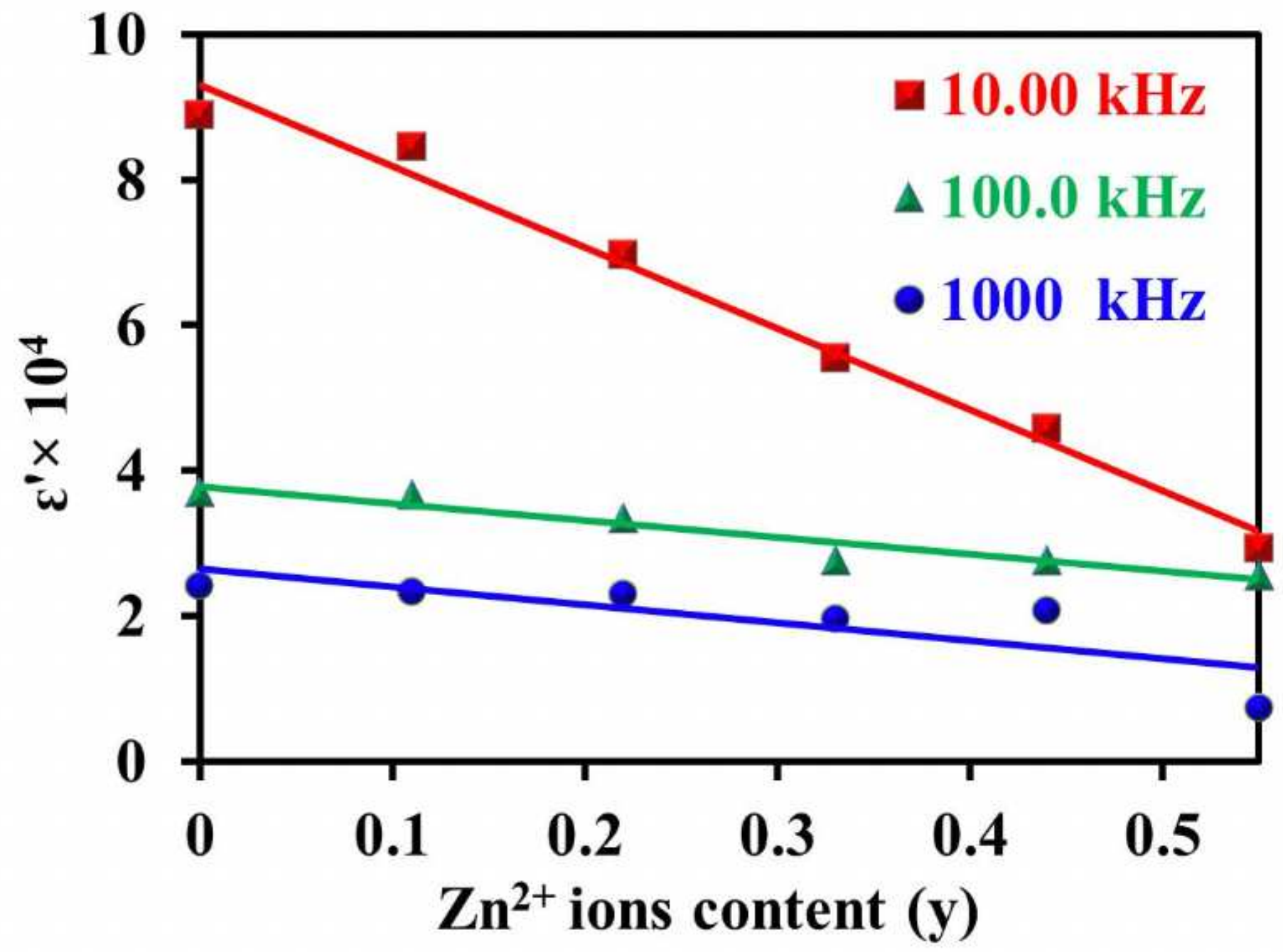

Figure 12

The dielectric constant $(\varepsilon /)$ versus $\mathrm{Zn}$ content for the CoZn ferrite nano-particles as a function of frequency. 


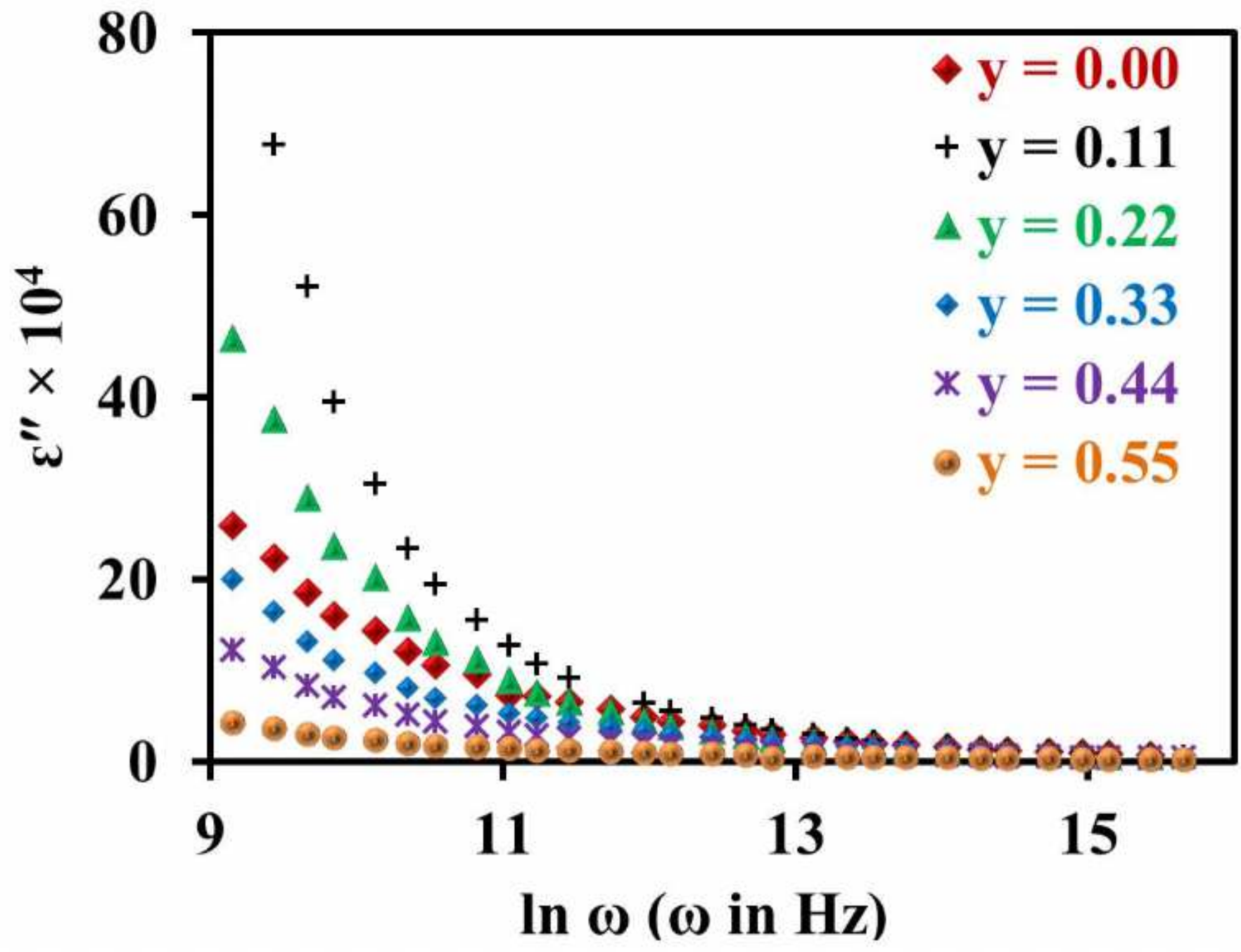

Figure 13

Dielectric loss factor of CoZn ferrite nanoparticles versus frequency as a function of $\mathrm{Zn} 2+$ ions. 


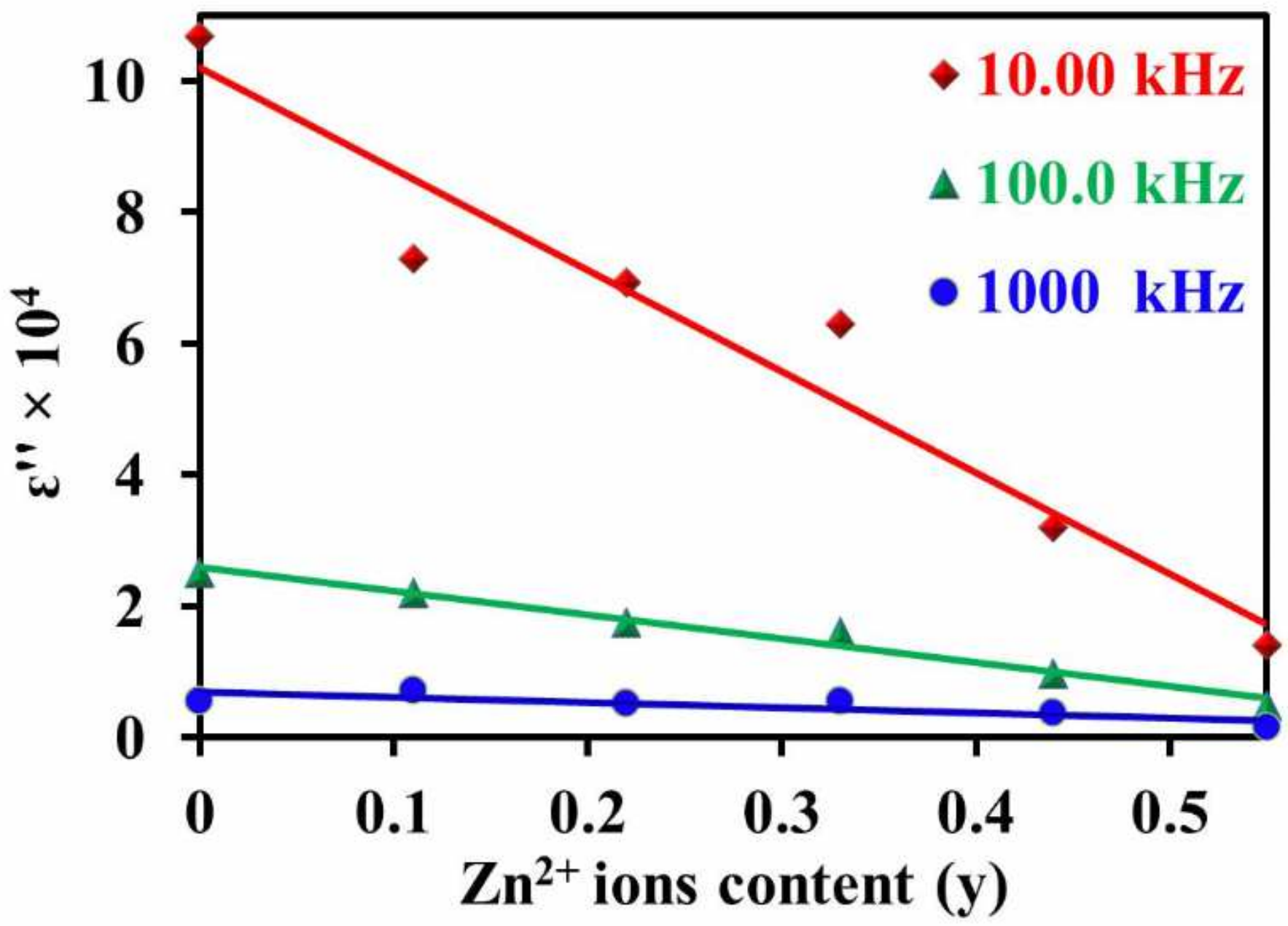

Figure 14

The dielectric loss $(\varepsilon / /)$ versus Zn2+ ions for CoZn ferrite nanoparticles as a function to $(10,100$ and 1000) $\mathrm{kHz}$ frequencies. 


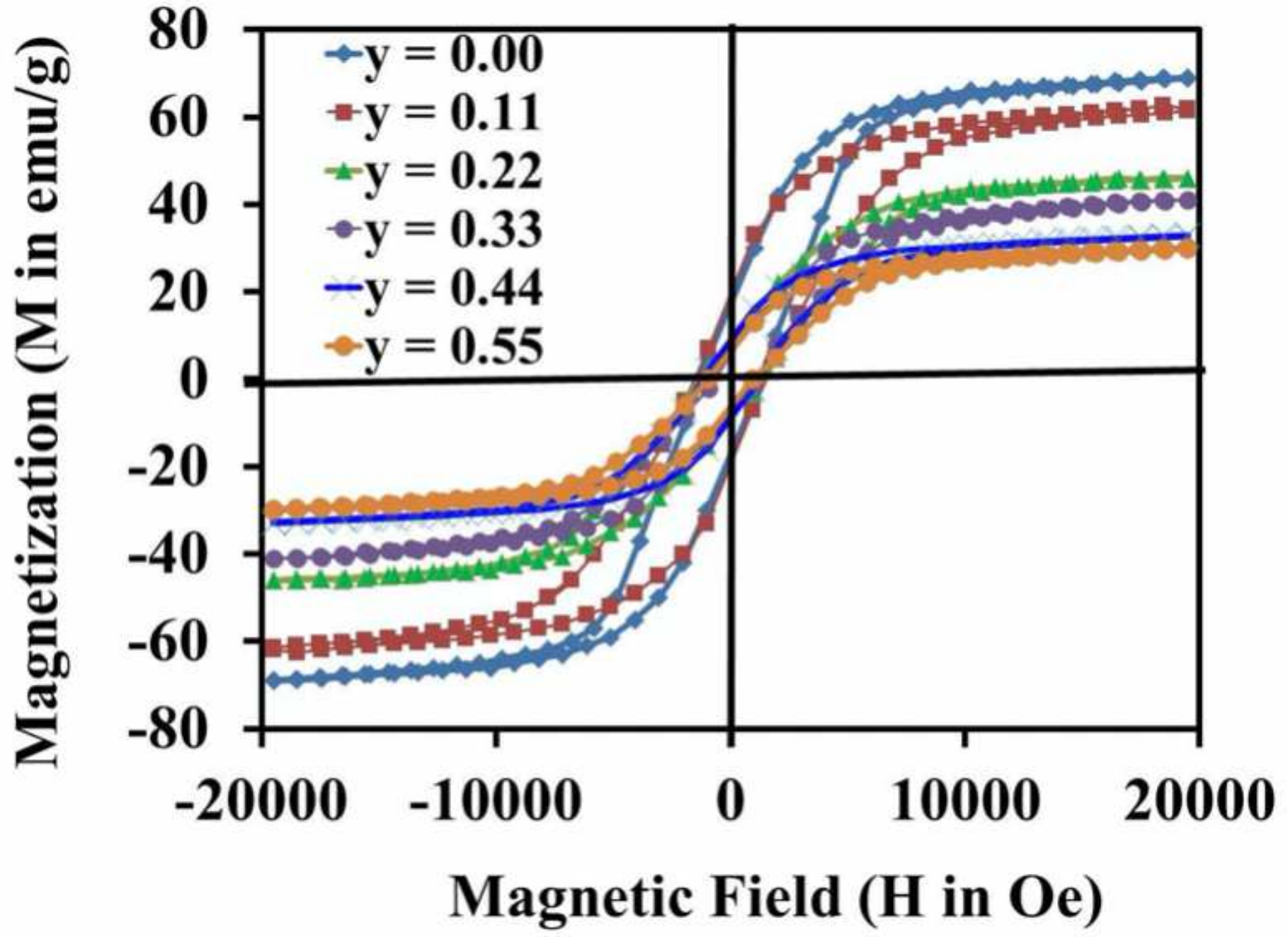

Figure 15

Magnetic characterization of CoZn ferrite nanoparticles as a function of $\mathrm{Zn} 2+$ ions. 

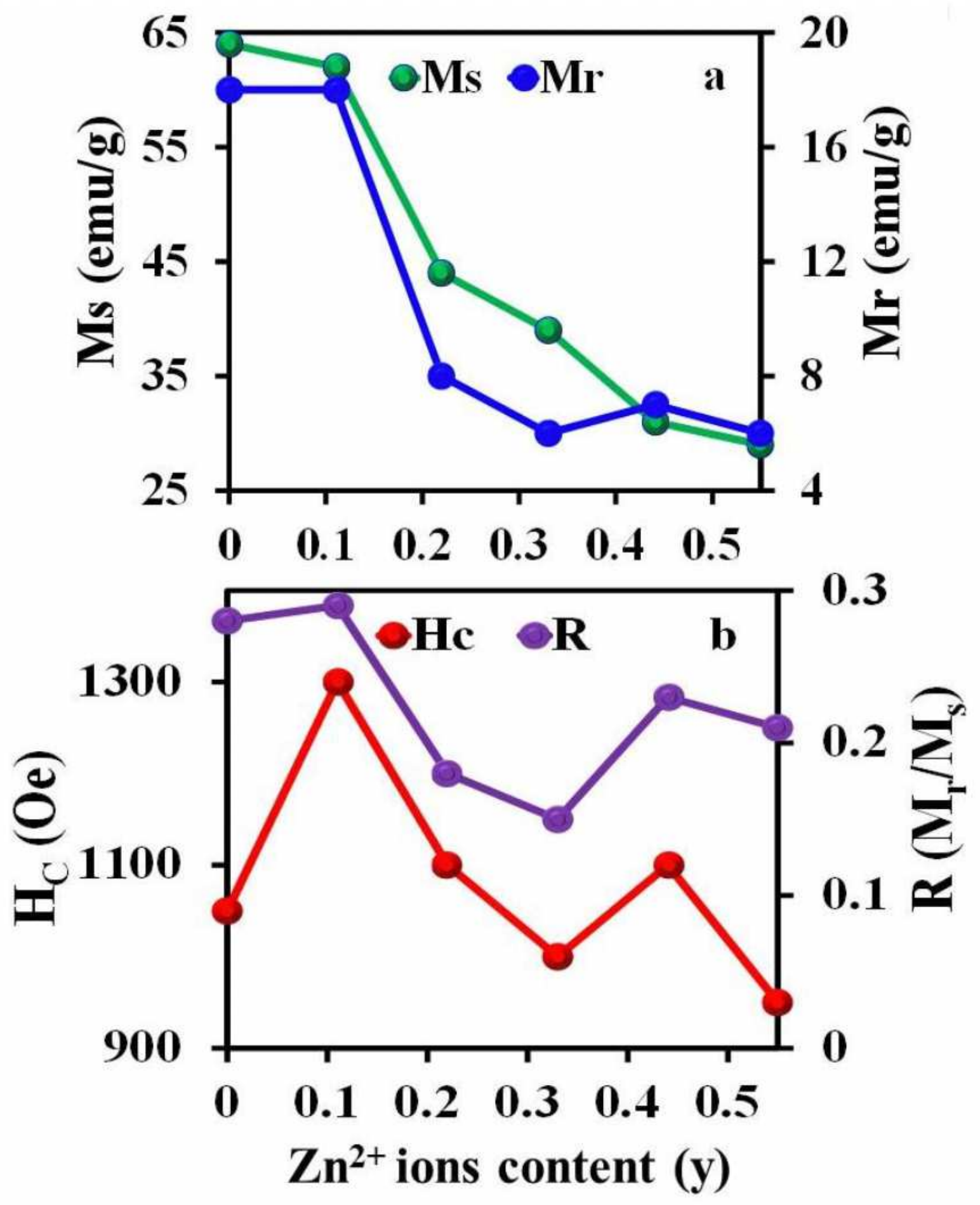

Figure 16

$(a, b): a)$ Remanence and saturation magnetization b) squareness ratio and coercivity of CoZn ferrite nanoparticles as a function of $\mathrm{Zn} 2+$ ions. 

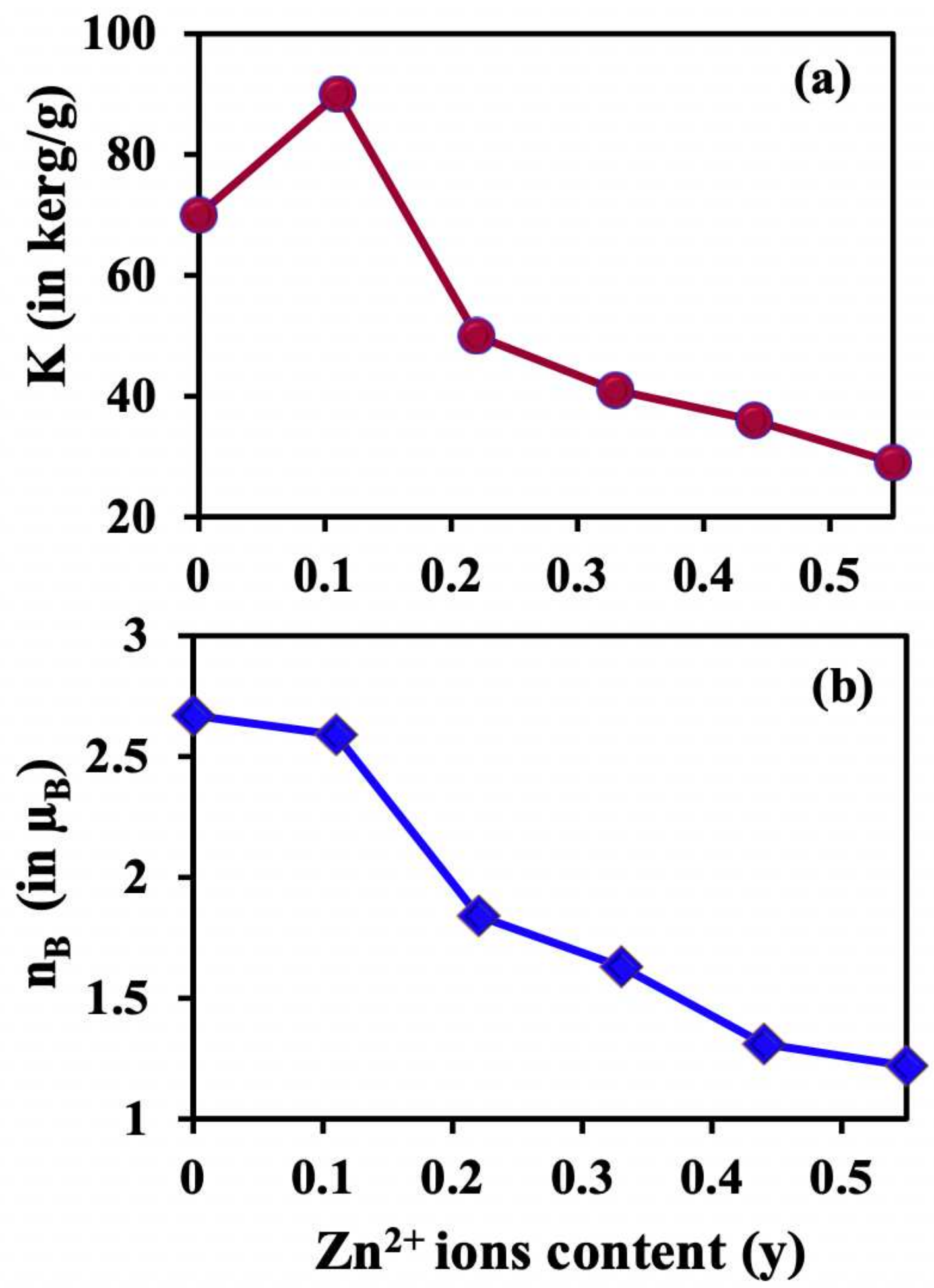

Figure 17

$(a, b)$ : a) Magnetic anisotropy constant and b) magnetic moments of CoZn ferrite as a function of Zn2+ ions. 


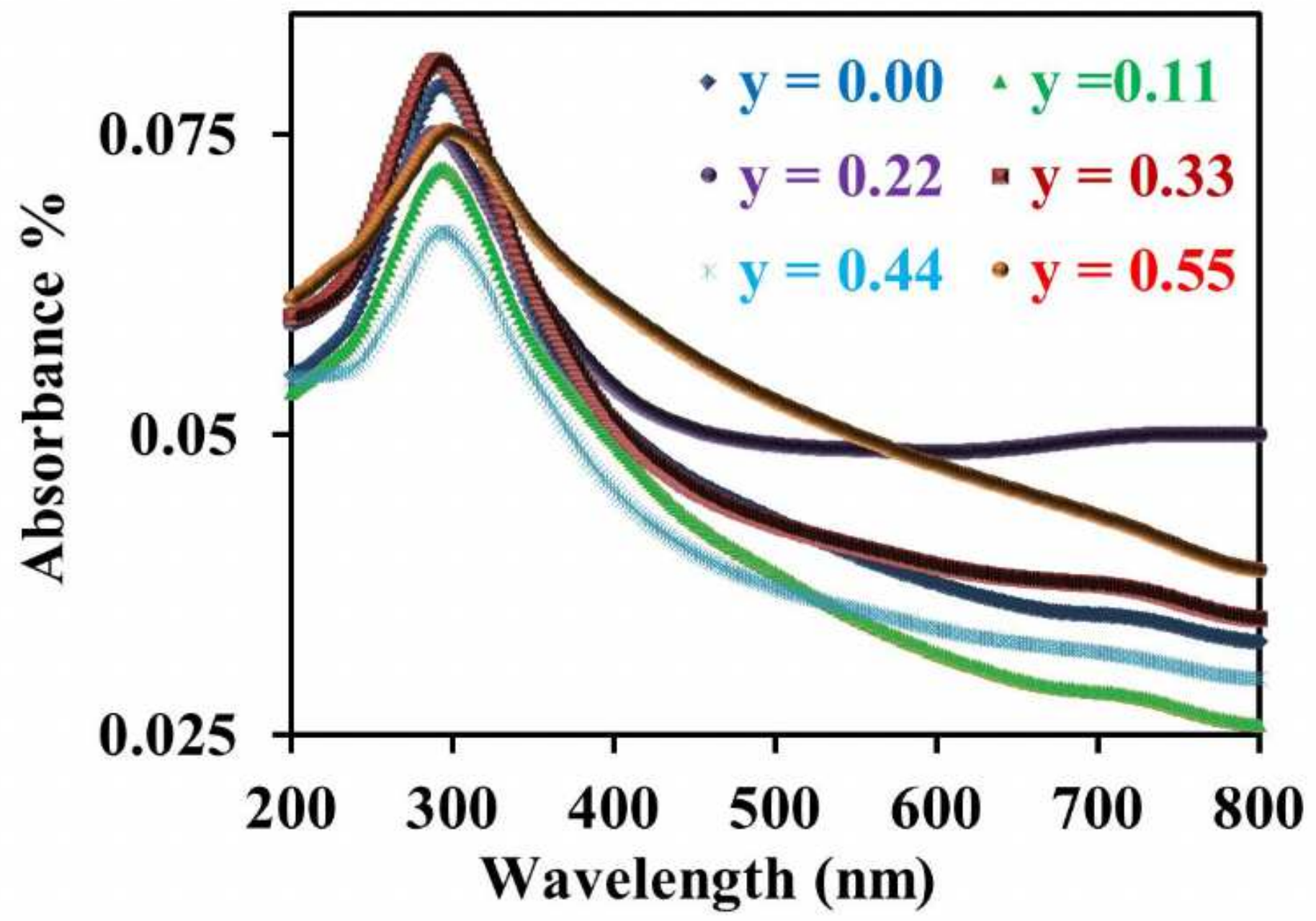

Figure 18

The absorbance spectra of ferrofluid based on CoZn ferrite nanoparticles samples as a function of Zn2+ ions. 


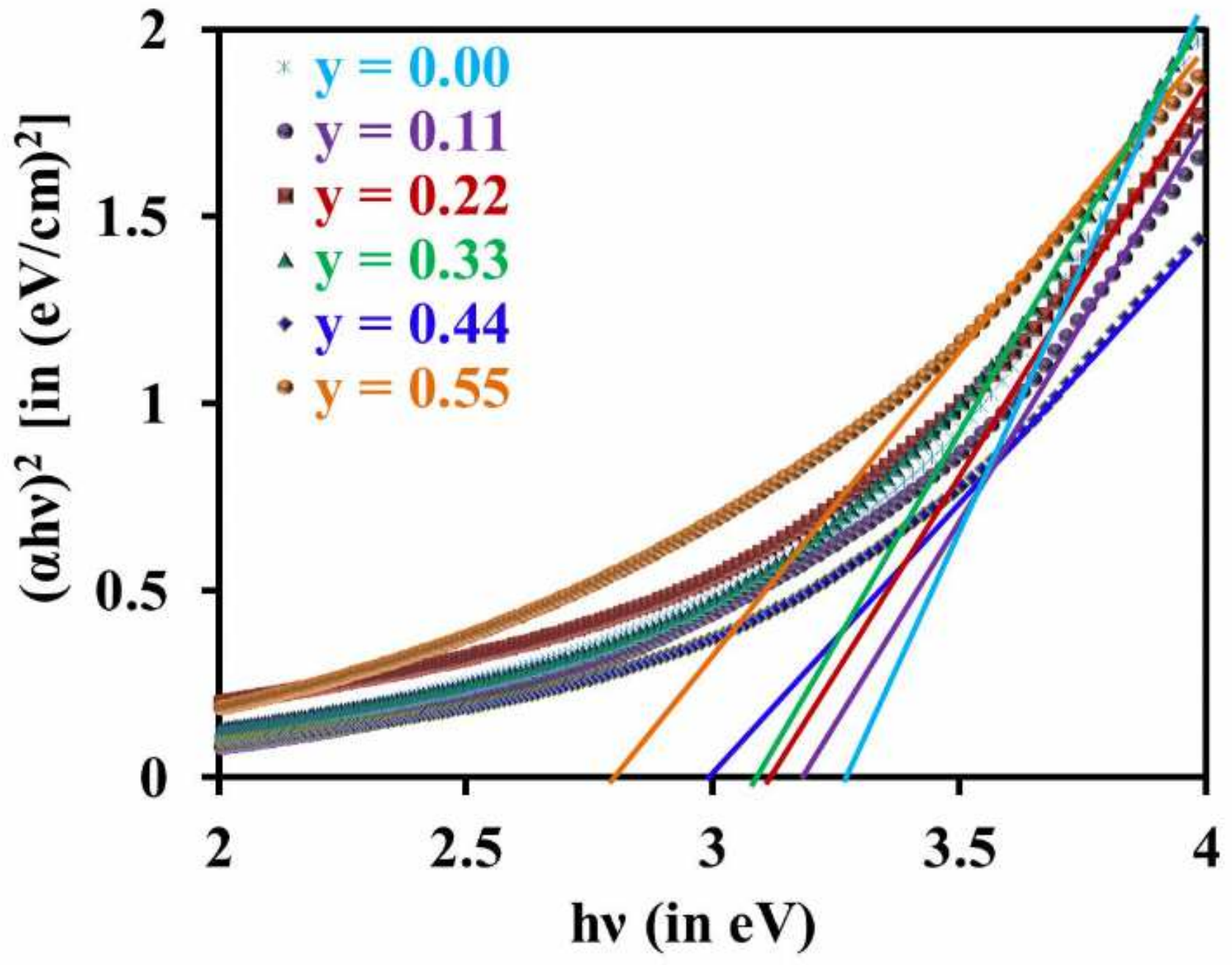

Figure 19

(avh)2 versus photon energy (hv) of ferrofluid based on CoZn ferrite nanoparticles samples as a function of $\mathrm{Zn} 2+$ ions. 